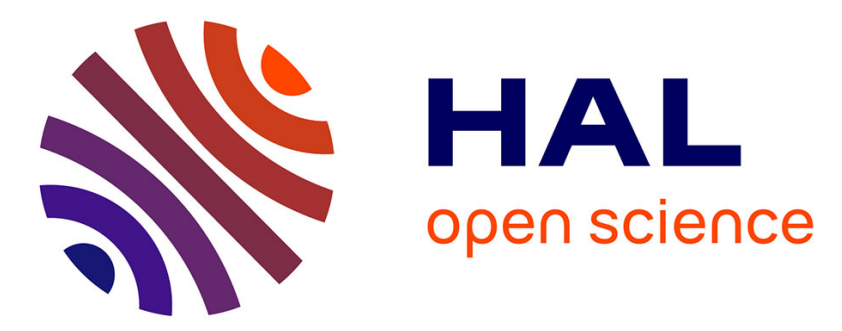

\title{
Experimental evaluation of contact stress during cold rolling process with optical fiber Bragg gratings sensors measurements and fast inverse method
}

Daniel Weisz-Patrault, Laurent Maurin, Nicolas Legrand, Anas Ben Salem, Abdelkebir Ait Bengrir

\section{To cite this version:}

Daniel Weisz-Patrault, Laurent Maurin, Nicolas Legrand, Anas Ben Salem, Abdelkebir Ait Bengrir. Experimental evaluation of contact stress during cold rolling process with optical fiber Bragg gratings sensors measurements and fast inverse method. Journal of Materials Processing Technology, 2015, 223, pp.105-123. 10.1016/j.jmatprotec.2015.03.047 . hal-01275175

\section{HAL Id: hal-01275175 \\ https://hal.science/hal-01275175}

Submitted on 3 Mar 2016

HAL is a multi-disciplinary open access archive for the deposit and dissemination of scientific research documents, whether they are published or not. The documents may come from teaching and research institutions in France or abroad, or from public or private research centers.
L'archive ouverte pluridisciplinaire HAL, est destinée au dépôt et à la diffusion de documents scientifiques de niveau recherche, publiés ou non, émanant des établissements d'enseignement et de recherche français ou étrangers, des laboratoires publics ou privés. 


\title{
Experimental Evaluation of Contact Stress During Cold Rolling Process with Optical Fiber Bragg Gratings Sensors Measurements and Fast Inverse Method
}

\author{
Daniel Weisz-Patrault ${ }^{\mathrm{a}}$, Laurent Maurin ${ }^{\mathrm{b}}$, Nicolas Legrand $^{\mathrm{c}}$, Anas Ben Salem ${ }^{\mathrm{c}}$, Abdelkebir Ait Bengrir $^{\mathrm{c}}$ \\ ${ }^{a}$ Laboratoire de Mécanique des Solides, CNRS UMR 7649, École Polytechnique, F-91128 Palaiseau, France. \\ ${ }^{b}$ CEA, LIST, Laboratoire de Mesures Optiques, F-91191 Gif-sur-Yvette, France. \\ ${ }^{c}$ ArcelorMittal Global Research \& Development, Maizières Process, F-57283 Maizières-lès-Metz, France.
}

\begin{abstract}
There is a strategic importance for the steel rolling industry to get a better understanding of the strip-roll interaction to improve roll-gap models, increase strip quality and decrease roll degradation. This requires roll-gap sensors able to measure this interaction under industrial rolling conditions and in real time in order to propose a feed-back control of process parameters. To reach these goals, this paper proposes a new roll-gap friction sensor based on an inverse method that interprets Optical Fiber Bragg Gratings (FBG) strain measurements under the roll surface (fully embedded), which enables to evaluate contact stresses with very short computation times, compatible with real-time interpretation. This elastic inverse method is analytical and relies on plane-strain and isothermal assumptions. The experimental apparatus is detailed, technical issues are clearly exposed as well as calibration procedures. Several pilot cold rolling tests have been performed at various rolling speeds and different strip thicknesses in order to demonstrate the industrial feasibility. Resulting evaluations of contact stresses are then compared with numerical simulations. Reasonable agreement is obtained for normal stress (i.e., pressure) but not for shear stress (only an order of magnitude is obtained).
\end{abstract}

Keywords:

Inverse method, Rolling process, Optical Fiber, Contact stress

Table 1: Nomenclature

\begin{tabular}{|ll|}
\hline$R_{s}$ & Outer radius (radius of the roll) \\
$R_{m}$ & Inner radius (radius of the measurements by Optical Fiber) \\
$d$ & Depth of Optical Fiber Bragg Grating Sensors \\
$L$ & Roll width \\
$l$ & Strip width \\
$r, \theta$ & Polar coordinates \\
$z=r \exp (i \theta)$ & Complex coordinate \\
$\Phi, \Psi$ & Holomorphic potential \\
$\varepsilon_{r r}^{m}, \varepsilon_{45}^{m}, \varepsilon_{\theta \theta}^{m}$ & Measured strains at the inner radius $R_{m}$ \\
$\varepsilon_{r r}, \varepsilon_{r \theta}, \varepsilon_{\theta \theta}$ & Strain tensor in the roll \\
$\sigma_{r r}, \sigma_{r \theta}, \sigma_{\theta \theta}$ & Stress tensor in the roll \\
$\lambda, \mu$ & Lamé coefficients \\
$E, v$ & Young and Poisson moduli \\
$\omega$ & Rotation speed \\
$f$ & Data acquisition frequency \\
$t_{0}$ & Strip entry thickness \\
$t_{1}$ & Strip exit thickness \\
$T=\frac{t_{0}-t_{1}}{t_{1}}$ & Thickness reduction ratio \\
$l_{C}$ & Contact length \\
$F_{R}$ & Rolling force \\
&
\end{tabular}




\section{Introduction}

Future customer requirements for higher quality of flat rolled products (i.e. strip thickness, strip flatness and strip surface free from defects) need a better understanding of the interaction between strip deformation in the roll bite and work roll surface (Figure 1). This need is also due to the current trend of rolling mills to combine higher rolling speeds, larger reduction, harder steel grades and thinner rolled strips, that all affect the three strip qualities (thickness, flatness and surface). The final goal is to decrease product yield associated to these rolled strip quality defects and to improve mill productivity by minimizing roll degradation. Typically, three main rolling conditions are used to produce flat steel products: hot, cold and temper rolling. Thick strips (thickness from $30 \mathrm{~cm}$ to $1 \mathrm{~cm}$ ) are rolled at around $1500 \mathrm{~K}$ under hot rolling conditions. The contact between the strip and the roll is a few centimeters long. Thinner strips (thickness from $5 \mathrm{~mm}$ to $1 \mathrm{~mm}$ ) are rolled at around $400 \mathrm{~K}$ under cold rolling conditions. Shorter contact lengths are obtained (around $10 \mathrm{~mm}$ ). Finishing steps, for packing for instance, are done under temper rolling conditions for very thin strips (a few hundreds of micrometers) with very short contact lengths (a few millimeters). Product quality is quantified by terms of flatness, defect free surface and thickness homogeneity. The different rolled materials (low or high alloy steels, low or high carbon steels, stainless or special steels) behave differently with respect to defects. Rotation speed of work rolls, rolling force (pressure applied by backup rolls), incoming strip speed, strip temperature, cooling and lubrication systems orientation are significant parameters regarding quality issues. Modern rolling mills combine higher rolling speeds, larger reduction ratios, harder steel grades and thinner rolled strips. Empirical settings do not apply anymore, thus to ensure a better product quality, knowledge of friction and lubrication in the roll gap becomes a very significant issue. Indeed, unknown shear stress and normal pressure as well as lubrication conditions take place in the strip/roll contact, where plastic deformations are generated, determining product quality. Many numerical simulations have been developed in order to characterize contact conditions as a function of rolling parameters. An interesting review of numerical simulations dedicated to the rolling process has been published by Montmitonnet (2006). For example, Jiang and Tieu (2001) proposed a rigid plastic/visco-plastic FEM and Hacquin (1996) published a 3D thermomechanical strip/roll stack coupled model called LAM3/TEC3 developed by Cemef, Transvalor, ArcelorMittal Research and Alcan. Abdelkhalek et al. (2011) computed the post-bite buckling of the strip, which is added to the older simulation of Hacquin (1996), in order to predict accurately flatness defects. Shahani et al. (2009) simulated a hot rolling process of aluminum by FEM and used an artificial neural network in order to predict the behavior of the strip during the rolling process (the artificial neural network being trained by the simulation). Numerical simulations adapted for particular hot rolling of large rings have been proposed by Wang et al. (2009).

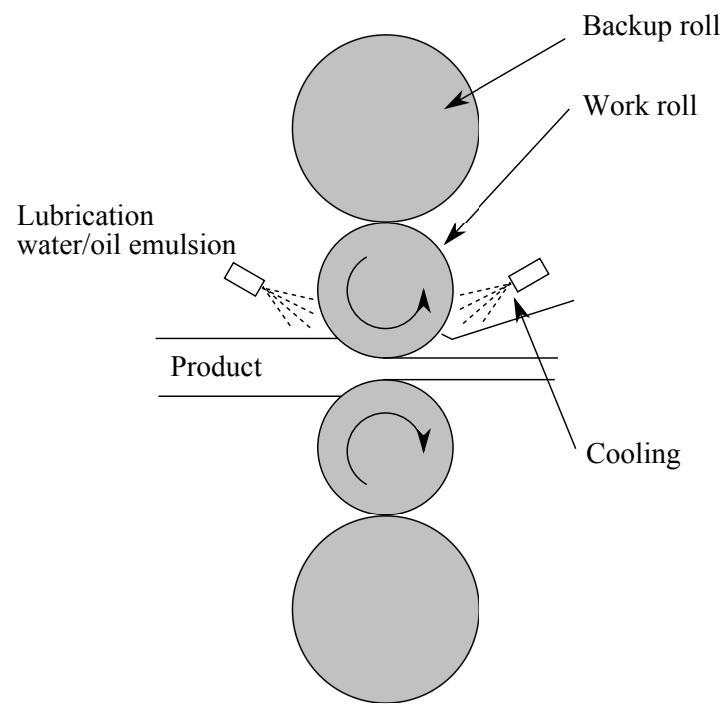

Figure 1: Rolling process

Such predictive models are necessary to understand phenomena (material flow in the roll gap, strain, stress and temperature rate fields) in order to establish rolling strategies for better productivity and quality. However, 
contact conditions (friction) of these numerical simulations do not have experimental validation in industrial or semi-industrial conditions. Moreover, the roll-strip contact is usually described by Coulomb or Tresca friction laws which are over-simplified to describe the complexity of the interface. Furthermore, a closed-loop control of rolling parameters depending on real-time measurements of contact conditions would be a substantial improvement of the process. Thus, the development of one-line roll gap sensors adapted for measuring in real-time contact stresses (pressure and shear stresses) is motivated by this double issue: model validation on the one hand and monitoring and controlling rolling parameters through feed back control on the other hand. To reach these goals, a European project RFS-PR-08051 (2014) has been launched with the aim to develop three complementary roll gap sensors for measuring simultaneously the mechanical, thermal and lubrication conditions at the roll-strip interface. The present work, which is part of this European project, presents the development of the mechanical sensor for measuring contact stress during pilot rolling tests. Pin sensors already provide measurements of contact stresses, although the presence of the pin disturbs the local lubricant flow at the interface, and the contact strongly marks the strip; industrial use is therefore impossible. Nevertheless, many investigators have designed direct friction pin sensors such as Jeswiet and Rice (1982) for normal stress or Lu et al. (2002) for shear stress or Andersen et al. (2001) who developed a commercial transducer. An indirect measurement that does not degrade contact conditions has been preferred in this study. More precisely an inverse method, that interprets strain measurements under the roll surface performed by Optical Fiber Sensors fully embedded inside the roll body, has been developed. Consequently, marks on the strip are limited and contact conditions are preserved. Technical issues related to Optical Fiber Sensors insertion under the roll surface, as well as equipment and design are detailed. A calibration procedure is proposed and clearly exposed. Then, pilot rolling tests are presented and the evaluation of contact stresses obtained by inverse method is compared with numerical simulations done with LAM3/TEC3 proposed by Hacquin (1996). In previous works, Weisz-Patrault et al. (2011) developed an analytical inverse method adapted for rolling processes that interprets stresses at only one position under the roll surface, in order to obtain contact stresses. Weisz-Patrault et al. (2012a) also proposed an inverse method that interprets temperature data under the roll surface in order to infer heat fluxes in the roll gap, and a thermoelastic coupling have been proposed by Weisz-Patrault et al. (2013a). An extension in three dimensions (with several points aligned along the roll axis) has been also developed by Weisz-Patrault et al. (2013b) for stresses and Weisz-Patrault et al. (2014b) for temperature. Pilot tests have been performed for thermal inverse problems dedicated to heat flux determination in the roll gap by Weisz-Patrault et al. (2012b) and Legrand et al. (2012a) with detailed experimental apparatus (insertion of the thermocouple under the roll surface etc...) and calibration procedures, and by Legrand et al. (2013) with a specific study on thermal fatigue of rolls. More recently, Weisz-Patrault (2015) proposed a semi-analytical inverse method based on conformal mapping techniques applied for latent flatness defect detection during rolling process. In this paper, contact stresses are evaluated through strain measurements obtained by several Optical Fiber Sensors inserted into the roll, at only one location under the roll surface (around $2 \mathrm{~mm}$ under the surface). An isothermal assumption is made since cold rolling tests are studied here: temperature increase in the roll bite is sufficiently moderate not to propagate at sub-surface so that these sensors measure only the mechanical roll strain. The inverse method used for inputs interpretation is based on the isothermal inverse method proposed by WeiszPatrault et al. (2011), however a substantial adaptation was required in order to deal with some measurement issues of an Optical Fiber Sensor (radial strain measurement). Thus, additional mathematical developments are detailed in this study. In the field of inverse methods dedicated to rolling processes, one can mention the work of Schnur and Zabaras (1990) and Bezerra and Saigal (1995), respectively based on Finite Element Method (FEM) and Boundary Element Method (BEM) and iterative calculation. However, computation times exhibited by these methods are incompatible with real-time interpretation, and no conclusive tests have been done with severe rolling conditions (i.e., small contact length and steep stress gradient). An analytical inverse method has been proposed by Meierhofer and Stelson (1987) and evaluated by simulation by Legrand et al. (2012b) on severe rolling conditions. Results are acceptable, however computation times are incompatible with real-time interpretation and technical issues are very limiting because two sets of Optical Fiber Sensors are needed at two different radii under the roll surface. On the contrary, the inverse method proposed by Weisz-Patrault et al. (2011) and adapted in this paper, enables a real-time computation and simplifies significantly the instrumentation of the work roll with only one set of Optical Fiber Sensors inserted under the roll surface.

\section{Inverse method}

In this section, general principles that underlie the inverse method are presented as well as specific developments, considering the fact that the radial Optical Fiber Sensor was not usable as explained in Section 4. The original inverse method published by Weisz-Patrault et al. (2011) was to measure radial and shear stresses under 
the roll surface (at a radius $R_{m}$ where $m$ means measured) with three Optical Fiber Sensors: radial, circumferential and at 45 degrees, so that a strain gauge is obtained and the local sub-surface strain tensor of the work roll can be measured at one inner roll radius. The three sensors are sufficiently close to each other, so that only one measurement point can be considered, thus successive measurements are performed during each cycle using the rotation of the work roll, as presented in Figure 2a. It is assumed that contact stresses evolution is sufficiently slow, so that during each cycle, contact stresses are roughly time-independent even though it can evolve from cycle to cycle. An analytical solution based on series expansion is determined in the sub-domain defined by the disk of radius $R_{m}$. Since the solution exists in the whole domain (disk of radius $R_{s}>R_{m}$ ), fields are extended by continuity towards the roll surface, and especially at radius $R_{s}$, where contact stresses are inferred as shown in Figure $2 \mathrm{~b}$.

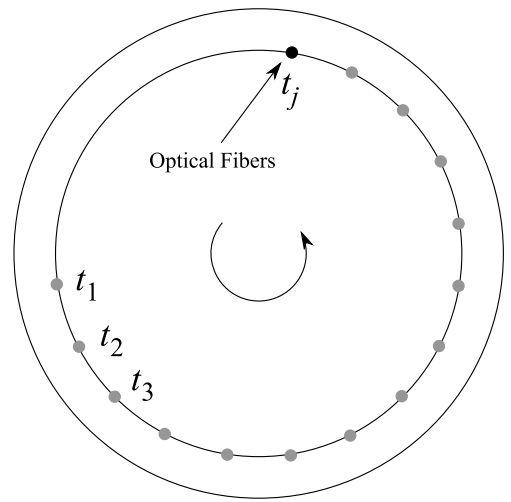

(a) Successive measurements

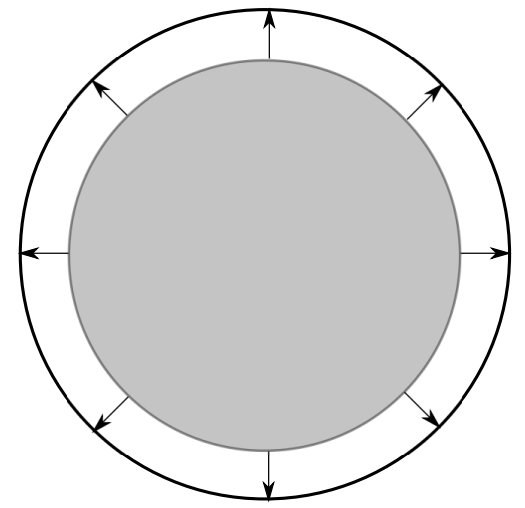

(b) Extension by continuity

Figure 2: Principle of inner roll successive measurements and their extension by continuity to roll surface

The analytical solution relies on plane strain assumption and elastic calculations. Muskhelishvili (1953) demonstrated, on the basis of Airy's potential theory, that elastic plane problems can be written with complex formalism. Weisz-Patrault et al. (2014a) published recently an extension in 3D of this classical elastic complex formalism, using the 4D quaternionic algebra and the concept of monogenic functions (extension of holomorphy in quaternionic algebra). However, since only one set of Optical Fiber Sensors is inserted under the roll surface at the middle of the axial direction, the classical complex formulas under plane strains assumption are used as follows:

$$
\left\{\begin{array}{l}
\sigma_{r r}+\sigma_{\theta \theta}=2(\Phi(z)+\overline{\Phi(z)}) \\
-\sigma_{r r}+\sigma_{\theta \theta}+2 i \sigma_{r \theta}=2 \exp (2 i \theta)\left(\Psi(z)+\bar{z} \Phi^{\prime}(z)\right)
\end{array}\right.
$$

where $\sigma_{r r}, \sigma_{r \theta}$ and $\sigma_{\theta \theta}$ represent the stress field, $z=r \exp (i \theta)$ represents the complex coordinates and $\Phi$ and $\Psi$ are two holomorphic potentials to be determined by means of the measurements. The holomorphy of both potentials on a disk enables to write power series expansions:

$$
\Phi(z)=\sum_{k=0}^{+\infty} \Phi_{k}\left(\frac{z}{R_{m}}\right)^{k} \quad \text { and } \quad \Psi(z)=\sum_{k=0}^{+\infty} \Psi_{k}\left(\frac{z}{R_{m}}\right)^{k}
$$

Hence:

$$
\left\{\begin{array}{l}
\sigma_{r r}(r, \theta)+\sigma_{\theta \theta}(r, \theta)=2 \sum_{k=0}^{+\infty}\left(\frac{r}{R_{m}}\right)^{k}\left(\Phi_{k} \exp (i k \theta)+\overline{\Phi_{k}} \exp (-i k \theta)\right) \\
-\sigma_{r r}(r, \theta)+\sigma_{\theta \theta}(r, \theta)+2 i \sigma_{r \theta}(r, \theta)=2 \sum_{k=0}^{+\infty}\left(\frac{r}{R_{m}}\right)^{k}\left(\Psi_{k} \exp (i(k+2) \theta)+k \Phi_{k} \exp (i k \theta)\right)
\end{array}\right.
$$

Unknown coefficients are determined with the measured condition, that is to say that at the inner radius $R_{m}$ radial and shear stresses $\sigma_{r r}\left(R_{m}, \theta\right)$ and $\sigma_{r \theta}\left(R_{m}, \theta\right)$ should match measured radial and shear stresses denoted by $\sigma_{r r}^{m}(\theta)$ and $\sigma_{r \theta}^{m}(\theta)$ (where $m$ means measured). Since:

$$
\frac{1}{2 \pi} \int_{0}^{2 \pi} \exp (i k \theta) \mathrm{d} \theta=\left\{\begin{array}{lll}
1 & \text { if } & k=0 \\
0 & \text { if } & k \neq 0
\end{array}\right.
$$


coefficients are evaluated as follows:

$$
\left\{\begin{array}{l}
\Phi_{0}=\frac{1}{4 \pi} \int_{0}^{2 \pi} \sigma_{r r}^{m}(\theta) \mathrm{d} \theta \\
k \geq 1 \quad \Phi_{k}=\frac{1}{2 \pi} \int_{0}^{2 \pi} \frac{\sigma_{r r}^{m}(\theta)+i \sigma_{r \theta}^{m}(\theta)}{\exp (i k \theta)} \mathrm{d} \theta \\
k \geq 0 \quad \Psi_{k}=-\frac{1}{2 \pi} \int_{0}^{2 \pi} \frac{(2+k) \sigma_{r r}^{m}(\theta)+i k \sigma_{r \theta}^{m}(\theta)}{\exp (i(k+2) \theta)} \mathrm{d} \theta
\end{array}\right.
$$

These latter integrals can be computed very efficiently using Fast Fourier Transform (fft) as detailed by WeiszPatrault et al. (2011), which is the main reason of the very short computation times obtained with the presented method (time displayed by Scilab Enterprises (2012): 0.05 second for a quadcore CPU running at $2.8 \mathrm{GHz}$ ). However, Optical Fiber Bragg Gratings do not directly measure stresses, but strains and with three strain measurements in different directions, one can obtain stresses. However, as detailed in Section 4, the radial Fiber Bragg Grating measurements are not consistent with the two other strain measurements (circumferential and at 45 degrees), and cannot be used with confidence (this is mainly due to some gluing issues). Therefore to overcome this difficulty, the inverse method must be modified in order not to use the radial strain measurement. From (3) the stress tensor is obtained component wisely:

$$
\left\{\begin{array}{l}
\sigma_{r r}(r, \theta)=\frac{1}{2} \sum_{k=0}^{+\infty}\left(\frac{r}{R_{m}}\right)^{k}\left((2-k) \Phi_{k} \exp (i k \theta)+(2-k) \overline{\Phi_{k}} \exp (-i k \theta)-\Psi_{k} \exp (i(k+2) \theta)-\overline{\Psi_{k}} \exp (-i(k+2) \theta)\right) \\
\sigma_{r \theta}(r, \theta)=-\frac{1}{2 i} \sum_{k=0}^{+\infty}\left(\frac{r}{R_{m}}\right)^{k}\left(-k \Phi_{k} \exp (i k \theta)+k \overline{\Phi_{k}} \exp (-i k \theta)-\Psi_{k} \exp (i(k+2) \theta)+\overline{\Psi_{k}} \exp (-i(k+2) \theta)\right) \\
\sigma_{\theta \theta}(r, \theta)=\frac{1}{2} \sum_{k=0}^{+\infty}\left(\frac{r}{R_{m}}\right)^{k}\left((2+k) \Phi_{k} \exp (i k \theta)+(2+k) \overline{\Phi_{k}} \exp (-i k \theta)+\Psi_{k} \exp (i(k+2) \theta)+\overline{\Psi_{k}} \exp (-i(k+2) \theta)\right)
\end{array}\right.
$$

The isotropic behavior is given by:

$$
2 \mu \underline{\varepsilon}=\underline{\sigma}-\frac{\lambda}{3 \lambda+2 \mu} \operatorname{tr}(\underline{\boldsymbol{\sigma}}) \underline{\mathbf{1}}
$$

where bold symbols are vectors, bold underlined symbols are $2^{\text {nd }}$ order tensors, $\underline{\boldsymbol{\sigma}}$ is the stress tensor, $\underline{\boldsymbol{\varepsilon}}$ is the strain tensor, $\underline{1}$ is the identity tensor, $(\lambda, \mu)$ are Lamé coefficients. Thus, the strain tensor is obtained component wisely as a function of the unknown coefficients $\Phi_{k}$ and $\Psi_{k}$ :

$$
\left\{\begin{aligned}
2 \mu \varepsilon_{r r}(r, \theta) & =\sum_{k=0}^{+\infty}\left[\frac{1}{2}\left(\frac{r}{R_{m}}\right)^{k}\left((2-k) \Phi_{k} \exp (i k \theta)+(2-k) \overline{\Phi_{k}} \exp (-i k \theta)-\Psi_{k} \exp (i(k+2) \theta)-\overline{\Psi_{k}} \exp (-i(k+2) \theta)\right)\right. \\
& \left.-\left(\frac{r}{R_{m}}\right)^{k} \frac{\lambda}{\lambda+\mu}\left(\Phi_{k} \exp (i k \theta)+\overline{\Phi_{k}} \exp (-i k \theta)\right)\right] \\
2 \mu \varepsilon_{r \theta}(r, \theta) & =-\frac{1}{2 i} \sum_{k=0}^{+\infty}\left(\frac{r}{R_{m}}\right)^{k}\left(-k \Phi_{k} \exp (i k \theta)+k \overline{\Phi_{k}} \exp (-i k \theta)-\Psi_{k} \exp (i(k+2) \theta)+\overline{\Psi_{k}} \exp (-i(k+2) \theta)\right) \\
2 \mu \varepsilon_{\theta \theta}(r, \theta)= & \sum_{k=0}^{+\infty}\left[\frac{1}{2}\left(\frac{r}{R_{m}}\right)^{k}\left((2+k) \Phi_{k} \exp (i k \theta)+(2+k) \overline{\Phi_{k}} \exp (-i k \theta)+\Psi_{k} \exp (i(k+2) \theta)+\overline{\Psi_{k}} \exp (-i(k+2) \theta)\right)\right. \\
& \left.-\left(\frac{r}{R_{m}}\right)^{k} \frac{\lambda}{\lambda+\mu}\left(\Phi_{k} \exp (i k \theta)+\overline{\Phi_{k}} \exp (-i k \theta)\right)\right]
\end{aligned}\right.
$$

Fiber Bragg Gratings enable to measure at the inner radius $R_{m}$ the following strains: $\varepsilon_{r r}^{m}(\theta), \varepsilon_{45}^{m}(\theta)$ and $\varepsilon_{\theta \theta}^{m}(\theta)$ as shown in Figure 3. Thus, a simple tensorial calculation gives:

$$
\varepsilon_{45}=-\varepsilon_{r \theta}+\frac{\varepsilon_{r r}+\varepsilon_{\theta \theta}}{2}
$$




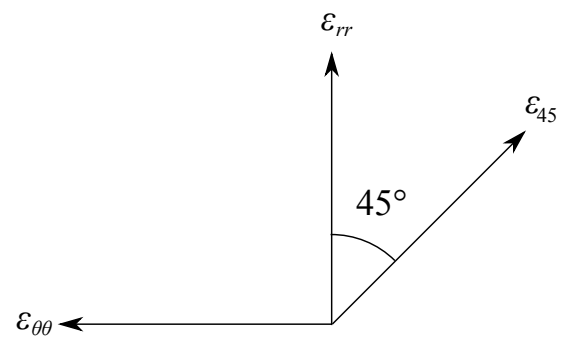

Figure 3: Optical Fiber Bragg Grating Sensors orientation

Thus, strains according to the available directions $\left(\varepsilon_{45}\right.$ and $\left.\varepsilon_{\theta \theta}\right)$ are written as follows:

$$
\left\{\begin{aligned}
2 \mu \varepsilon_{\theta \theta}(r, \theta) & =\sum_{k=0}^{+\infty}\left[\frac{1}{2}\left(\frac{r}{R_{m}}\right)^{k}\left((2+k) \Phi_{k} \exp (i k \theta)+(2+k) \overline{\Phi_{k}} \exp (-i k \theta)+\Psi_{k} \exp (i(k+2) \theta)+\overline{\Psi_{k}} \exp (-i(k+2) \theta)\right)\right. \\
& \left.-\left(\frac{r}{R_{m}}\right)^{k} \frac{\lambda}{\lambda+\mu}\left(\Phi_{k} \exp (i k \theta)+\overline{\Phi_{k}} \exp (-i k \theta)\right)\right] \\
2 \mu \varepsilon_{45}(r, \theta) & =\sum_{k=0}^{+\infty}\left[\frac{1}{2 i}\left(\frac{r}{R_{m}}\right)^{k}\left(-k \Phi_{k} \exp (i k \theta)+k \overline{\Phi_{k}} \exp (-i k \theta)-\Psi_{k} \exp (i(k+2) \theta)+\overline{\Psi_{k}} \exp (-i(k+2) \theta)\right)\right. \\
& \left.+\left(\frac{r}{R_{m}}\right)^{k} \frac{\mu}{\lambda+\mu}\left(\Phi_{k} \exp (i k \theta)+\overline{\Phi_{k}} \exp (-i k \theta)\right)\right]
\end{aligned}\right.
$$

The measured condition, which requires that calculated strains match measured strains, is introduced. Thus, measured strains are expressed at the inner radius in corresponding directions as a function of the unknown coefficients $\Phi_{k}$ and $\Psi_{k}$ :

$$
\forall k \geq 1,\left\{\begin{array}{l}
\frac{\mu}{\pi} \int_{0}^{2 \pi} \varepsilon_{\theta \theta}^{m}(\theta) \exp (-i k \theta) \mathrm{d} \theta=\Phi_{k}\left(\frac{2+k}{2}-\frac{\lambda}{\lambda+\mu}\right)+\frac{\Psi_{k-2}}{2} \\
\frac{\mu}{\pi} \int_{0}^{2 \pi} \varepsilon_{45}^{m}(\theta) \exp (-i k \theta) \mathrm{d} \theta=\Phi_{k}\left(-\frac{k}{2 i}+\frac{\mu}{\lambda+\mu}\right)-\frac{\Psi_{k-2}}{2 i}
\end{array}\right.
$$

Hence:

$$
\left\{\begin{array}{c}
\Phi_{0}=\frac{\lambda+\mu}{2 \pi} \int_{0}^{2 \pi} \varepsilon_{\theta \theta}^{m}(\theta) \mathrm{d} \theta=\frac{\lambda+\mu}{2 \pi} \int_{0}^{2 \pi} \varepsilon_{45}^{m}(\theta) \mathrm{d} \theta \\
\forall k \geq 1 \quad \Phi_{k}=\frac{(1+i)(\lambda+\mu)}{2 \pi} \int_{0}^{2 \pi} \frac{\varepsilon_{45}^{m}(\theta)-i \varepsilon_{\theta \theta}^{m}(\theta)}{\exp (i k \theta)} \mathrm{d} \theta \\
\forall k \geq 0 \quad \Psi_{k}=-\frac{(1+i)}{2 \pi} \int_{0}^{2 \pi} \frac{(2 \mu+(k+2)(\lambda+\mu)) \varepsilon_{45}^{m}(\theta)-(2 \mu+i(k+2)(\lambda+\mu)) \varepsilon_{\theta \theta}^{m}(\theta)}{\exp (i(k+2) \theta)} \mathrm{d} \theta
\end{array}\right.
$$

This latter expression (12) of coefficients $\Phi_{k}$ and $\Psi_{k}$ depends only on exploitable measured strains and replaces the expression (5). Obviously, the Fast Fourier Transform can be used as well for very efficient computations. Finally contact stresses (i.e., pressure and shear stresses) are determined by taking $r=R_{s}$ in (6).

Nevertheless, all inverse methods are ill-posed, in other words, there is a lack of stability: thus very small input variations (for example measurement noise or even quadrature errors) can lead to very large output variations. As explained by Weisz-Patrault et al. (2011), this inverse method using series expansions, the ill-posedness is easily identifiable. Indeed, the computation of coefficients $\Phi_{k}$ and $\Psi_{k}$ according to (12) leads to quadrature errors. Let explain the underlying ideas with a random error of order of magnitude $e>0$ : for each term of sums involved in (6), the error is amplified by $\left(R_{s} / R_{m}\right)^{k}$, thus the resulting stress components are roughly affected by the following error:

$$
e \times \sum_{k=0}^{N}\left(\frac{R_{s}}{R_{m}}\right)^{k} \underset{N \rightarrow+\infty}{\rightarrow}+\infty
$$

In order to overcome stability problems, regularization techniques are used. Most of the time for iterative methods that aim at minimizing a cost function representing the difference between measurements and computations, 
regularization consists in adding an additional condition in the cost function; for example the derivatives of the searched fields, which tend to smooth them, large oscillations being a typical clue of bad conditioning. For analytical inverse methods with series expansions, it is clear that regularization techniques simply consist in truncating sums. Two concurrent trends can be mentioned: convergence on the one hand: the truncation order should be large enough so that truncated sums are good approximations of corresponding infinite sums, and lack of stability on the other hand: the truncation order should not be too large so that amplified errors do not affect too much the solution. A compromise should be found. Weisz-Patrault et al. (2011) proposed a rule of thumb in order to determine automatically the appropriate truncation order with some simple criteria related to the inputs. However, amplified coefficients $\left|\Phi_{k}\right|\left(R_{s} / R_{m}\right)^{k}$ and $\left|\Psi_{k}\right|\left(R_{S} / R_{m}\right)^{k}$ are more directly related to ill-posedness. Thus, the best option is likely to truncate sums according to the evolution of these amplified coefficients as shown in Figure 14 that corresponds to pilot tests described in Section 5. In this paper, the truncation order has been determined manually. No algorithm that automatically selects the appropriate truncation order, according to the amplified coefficients, has been developed, however this aspect should be investigated for future industrial applications.

\section{Experimental apparatus}

In this section the measurement loop is described. Its underlying principle relies on Optical Fiber Bragg Grating (FBG) strain sensors. Mechanical performances of FBG sensors such as tensile and fatigue properties have been studied recently by Frieling and Walther (2013). In this study, FBG sensors are glued into blind bores beneath the surface of a $\varnothing 42 \mathrm{~mm}$ diameter cylindrical piece of metal (the plug). This plug is then inserted into the roll as shown in Figure 4a in order to perform real-time strain measurements during the rolling process, a few hundreds of $\mu \mathrm{m}$ close to the roll contact surface. In this section the measurement loop is described. Its underlying principle relies on Optical Fiber Bragg Grating (FBG) strain sensors. Mechanical performances of FBGs such as tensile and fatigue properties have been studied glued into blind bores beneath the surface of a $\varnothing 42 \mathrm{~mm}$ diameter cylindrical piece of metal (the plug). This plug is then inserted into the roll as shown in Figure 4a in order to perform real-time strain measurements during the rolling process, a few hundreds of $\mu \mathrm{m}$ close to the roll contact surface.

The FBG acts as a local sensor characterized by its Bragg wavelength $\lambda_{\text {Bragg }}=2 n_{\text {eff }} \Lambda$, where $n_{\text {eff }}$ is the effective refractive index of the core of the optical fiber, and $\Lambda$ the pitch of the grating. At a usual scale (a few tenths of Kelvin and a few hundreds of $\mu \mathrm{m} / \mathrm{m}$ ), this sensor is mainly sensitive to both temperature variations $\Delta T$ and longitudinal strain variations $\Delta \varepsilon$, and to a lesser extent, to hydrostatic pressure variations $\Delta P$ according to the following relationship (Ferdinand et al. (2009)):

$$
\frac{\Delta \lambda_{\text {Bragg }}}{\lambda_{\text {Bragg }}}=a \Delta \varepsilon+b \Delta T+c \Delta P \quad \text { with: }\left\{\begin{array}{ll}
a \simeq 0.78 \times 10^{-6} & (\mu \mathrm{m} / \mathrm{m})^{-1} \\
b \simeq 7.7 \times 10^{-6} & \mathrm{~K}^{-1} \\
c \simeq-2.94 \times 10^{-6} & \text { bar }^{-1}
\end{array} \quad\left(\lambda_{\text {Bragg }} \text { centered on 1550 nm }\right)\right.
$$

In our configuration, the wavelength shifts $\Delta \lambda_{\text {Bragg }}$ of the FBGs glued into the plug mainly depend on the longitudinal strain $\Delta \varepsilon$, even if an hydrostatic pressure effect could also be observed, but this last component is usually negligible in most applications, therefore leading to a first and simplified relationship:

$$
\frac{\Delta \lambda_{\text {Bragg }_{\{\Delta \varepsilon\}}}}{\lambda_{\text {Bragg }_{\{\Delta \varepsilon\}}}} \simeq a_{\{\Delta \varepsilon\}} \Delta \varepsilon+b_{\{\Delta \varepsilon\}} \Delta T+\underbrace{\overline{\mathcal{C}_{\Delta \varepsilon\}} \Delta P}}_{\text {neglected }}
$$

FBG strain sensitivity calibration experiments are first performed at room temperature on the optical fiber itself before being glued into the plug. To do so, calibrated masses $m$ are attached to the optical fiber, pulling with vertical force $F_{f}=m g$. In such configuration, the longitudinal strain $\Delta \varepsilon$ and the sensitivity $a$ can be expressed according to:

$$
\Delta \varepsilon(m)=\frac{4 m g}{E_{f} \pi \phi_{f}^{2}} \Longrightarrow a=\frac{\Delta \lambda_{\text {Bragg }}}{\lambda_{\text {Bragg }}} \frac{E_{f} \pi \phi_{f}^{2}}{4 m g} \quad \text { with: }\left\{\begin{array}{lll}
g & =9.81 \mathrm{~m} \cdot \mathrm{s}^{-2} & \text { gravitational acceleration } \\
\phi_{f}=125 \mu \mathrm{m} & \text { bare fiber diameter } \\
E_{f} \simeq 72 \mathrm{GPa} & \text { optical fiber Young's modulus }
\end{array}\right.
$$

Measurements performed with twelve different Fiber Bragg Gratings, with masses $m$ ranging from $0 \mathrm{~kg}$ (reference state) up to $0.263 \mathrm{~kg}$ (equivalent to $\Delta \varepsilon \simeq 0.29 \%$ which is greater than the yield strain of usual steel grades), give an average sensitivity $\langle a\rangle$ close to 0.72 with a standard deviation close to 0.008 , which is not significantly different from the usual 0.78 value (14). 
Strain gradients, especially in the radial direction during roll rotation, are very steep in the contact vicinity. Therefore, short $1 \mathrm{~mm}$ long FBGs were preferred (instead of classical $6^{+} \mathrm{mm}$ long FBGs) in order to limit as much as possible gradient effects leading to a stretch of the FBG reflected spectrum, hence to difficulties to accurately identify the characteristic Bragg wavelength $\lambda_{\text {Bragg. }}$. The other advantage of such short Fiber Bragg Gratings is a broader reflected spectrum, with a FWHM closer to $800 \mathrm{pm}$, in comparison to typically 250 pm for standard gratings (as detailed by Martinez (1999)). Optical measurement systems can therefore take benefit from additional information in the spectral domain, leading to a more accurate Bragg wavelength detection, despite the fact that significant less optical power is reflected by shorter gratings ${ }^{1}$.

From the practical point of view, gluing Optical Fibers in a $40 \mathrm{~mm}$ long and $400 \mu \mathrm{m}$ diameter hole, furthermore closed at its end ${ }^{2}$, is a technical challenge: this has been achieved using a syringe equipped with a precision tubing long enough to, first, inject the glue from the bottom of the hole in order to eliminate any bubble and wet the whole surface, and second, to accurately place the FBGs at their expected position below the external surface. At last, the glue is cured according to a specific recipe, taking also into account degassing issues (Figure 4b).

This $\varnothing 400 \mu \mathrm{m}$ hole diameter (in comparison, bare fiber diameter $\phi_{f}$ is equal to $\varnothing 125 \mu \mathrm{m}$ ) is in fact a good compromise between machining technical feasibility (length $v s$. diameter ratio is equal to 100) and relaxation times after mechanical compressions of the plug: this can be explained if we consider that strain transduction mechanisms from the plug to the FBGs mainly involve shear stresses, whose strength is roughly inversely proportional to the thickness of the film of glue surrounding the Optical Fibers (the thinner the better).

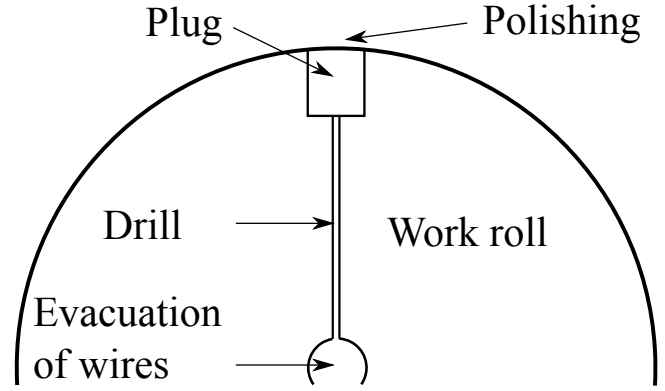

(a) Instrumented plug installed into the work roll

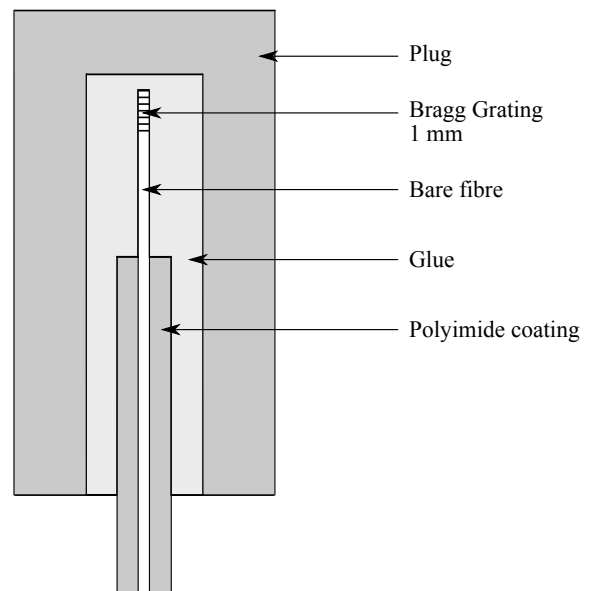

(b) Typical FBG position into plug's hole

Figure 4: Instrumented work roll, FBG sensors in the surface vicinity

Several tests have been performed to select the glue. The main criteria were the ability to get an homogenous bonding without air voids (as shown in Figure 5a) and to exhibit good fatigue performances to resist to fatigue solicitation during roll revolutions. Compression fatigue tests have also been performed with typically up to $10^{6}$ cycles at different strain levels $(60 \mu \mathrm{m} / \mathrm{m}, 120 \mu \mathrm{m} / \mathrm{m}, 600 \mu \mathrm{m} / \mathrm{m}$ and $1200 \mu \mathrm{m} / \mathrm{m})$ and different rates $(5 \mathrm{~Hz}, 10 \mathrm{~Hz}$, $15 \mathrm{~Hz}$ and $20 \mathrm{~Hz}$ ), compliant with rolling experiments (thermo-mechanical fatigue tests could be performed for hot rolling conditions in further investigations). Some samples used for these tests are presented in Figure 5b. Finally, amongst a set of four candidates, the glue that exhibited the best compromise in terms of bonding without significant residual strain gradients after cure (which may be due, but not exclusively, to the presence of voids), good fatigue performances was selected.

\footnotetext{
${ }^{1}$ Which may also require to add an optical amplifier in the measurement loop for a better signal to noise ratio.

${ }^{2}$ This is required to avoid significant marks on the strip during the rolling process.
} 


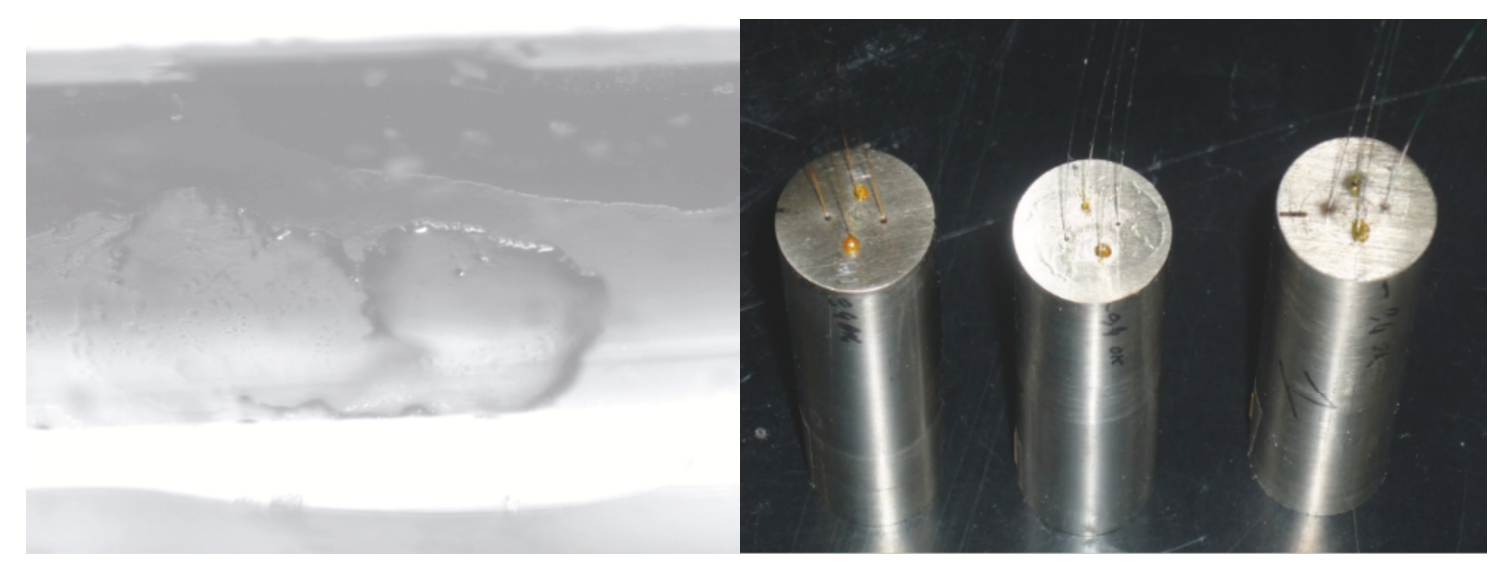

(a) Typical air void defect into the glue at the interface (b) Typical bodies used to test simultaneously four difwith a transparent precision tubing ferent glues during fatigue tests

Figure 5: Selecting the glue

As mentioned previously, three Optical Fiber Bragg Gratings dedicated to strain measurements are glued into the plug (Figure 6a). However, even if the problem is assumed to be isothermal in this paper dedicated to cold rolling process, this experimental apparatus is also planned to be used in hot rolling conditions: therefore, it will have to face very steep temperature gradients, generating additional thermal strains in the plug $^{3}$, and consequently along the FBGs. This must be taken into account.

Several solutions can be considered, but the easiest to implement is probably to use a fourth FBG free from stress located in the very close vicinity of the first three FBGs, therefore acting, once calibrated, as a local temperature sensor. The additional information $\lambda_{\text {Bragg }_{\{\Delta T\}}}$ provided by this grating, in combination with (15), can be used to compensate first order temperature cross-sensitivity effects on the strain measurements:

$$
\frac{\Delta \lambda_{\text {Bragg }_{\{\Delta T\}}}}{\lambda_{\operatorname{Bragg}_{\{\Delta T\}}}}=b_{\{\Delta T\}} \Delta T \Longrightarrow \Delta \varepsilon \simeq \frac{1}{a_{\{\Delta \varepsilon\}}}\left(\frac{\Delta \lambda_{\text {Bragg }_{\{\Delta \varepsilon\}}}}{\lambda_{\operatorname{Bragg}_{\{\Delta \varepsilon\}}}}-\frac{b_{\{\Delta \varepsilon\}}}{b_{\{\Delta T\}}} \frac{\Delta \lambda_{\operatorname{Bragg}_{\{\Delta T\}}}}{\lambda_{\operatorname{Bragg}_{\{\Delta T\}}}}\right)
$$

However, even if the four FBGs are very close one to another (Figure 6a), their measurements do not correspond exactly to the same physical area. This small distance between two gratings therefore introduces some time and space discrepancies in the measurements. This is all the more true in transient states, especially with steep temperature gradients, considering the fact that the time response and the sensitivity to temperature of a FBG dedicated to strain measurements (glued to the plug) are also different from the "free from stress" temperature compensation FBG. These discrepancies still exist in steady states, however in some extent, one can consider that they are reproducible from cycle to cycle, therefore enabling additional elaborated numerical compensation techniques to be implemented to take into account these phenomena.

The plug shown in Figure 6a has been designed keeping in mind that all the four out-coming Optical Fibers must be kept aligned with the plug axis (radial direction) in order to be easily routed (without any break) to the roll center and then to the external data acquisition station as detailed in the following. The FBG used for temperature compensation and the FBG measuring the radial strain $\varepsilon_{r r}^{m}$ are inserted one close to another into two separate holes aligned with the plug axis. The two other Optical Fibers dedicated to $\varepsilon_{\theta \theta}^{m}$ and $\varepsilon_{45}^{m}$ measurements are inserted into the plug according to a more complicated scheme in order to get the appropriate FBG orientations in the surface vicinity. The curvature radii are limited to $R_{\min }=10 \mathrm{~mm}$ to avoid mechanical fatigue breaks as well as significant optical signal power losses, two reasons which may prevent any measurement. Technically, such a complicated path cannot be drilled inside the plug body besides the fact that the Optical Fibers would be very difficult to insert. That is the reason why two slots on the sides of the plug sides are made with specific shapes at the bottom, then a thin hole is drilled from the slot with the right orientation to roll surface. Optical Fibers are inserted at the bottom of the slots, and then inserted and glued in the hole with the same procedure as the two radial ones. A picture of manufactured plugs is presented in Figure $6 \mathrm{~b}$.

\footnotetext{
${ }^{3}$ This additional thermal strain should be taken into account with a thermoelastic coupling as proposed by Weisz-Patrault et al. (2013a).
} 


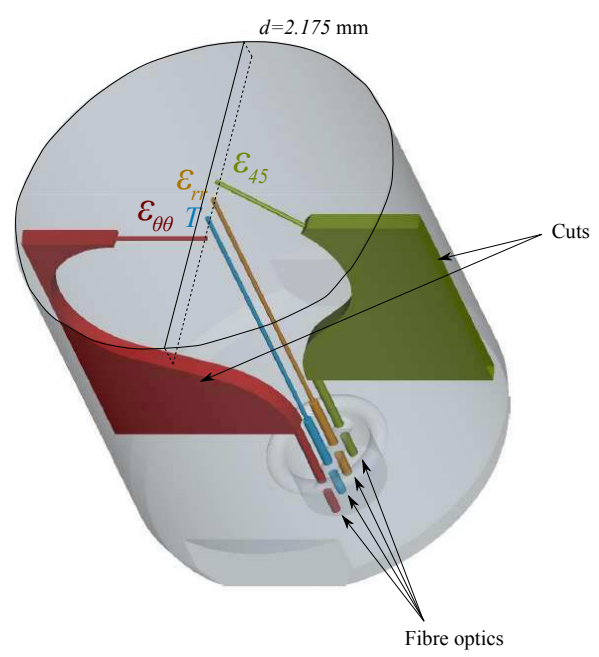

(a) 3D CAD plug design

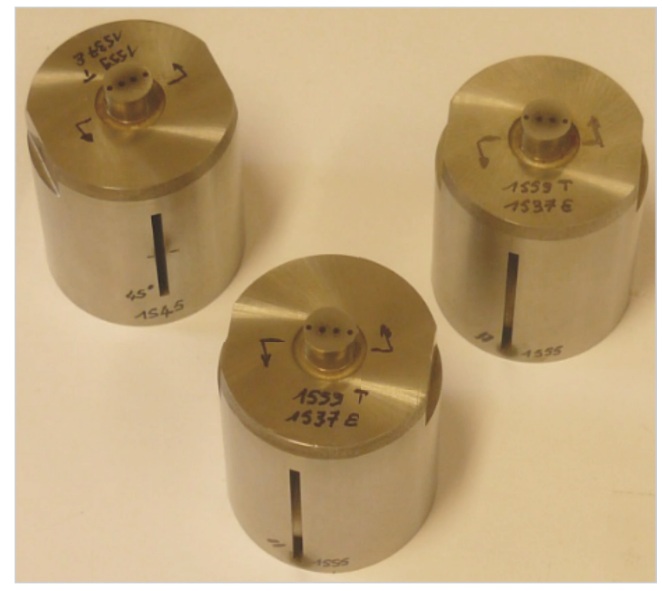

(b) Manufactured plugs

Figure 6: Plug design and the manufactured plugs with their 4 aligned holes for Optical Fibers insertion

Two successive Optical Fibers are spaced $1.25 \mathrm{~mm}$ along the axial direction. It is considered that the stress field is sufficiently homogeneous along the axial direction at this scale, so that one can consider all Optical Fibers at the same axial position. A first test of the plug before insertion inside the roll body is performed under press and a picture is presented in Figure 7a. FBGs responses present very good linearity as shown in Figure 7b, where $F$ is the vertical force (in Newton) applied by the press and $\varepsilon_{T}$ represents the deformation of the FBG free from stress dedicated to temperature cross-sensitivity compensation (no significant sensitivity under pressure at room temperature can be noticed in comparison with the other FBGs).

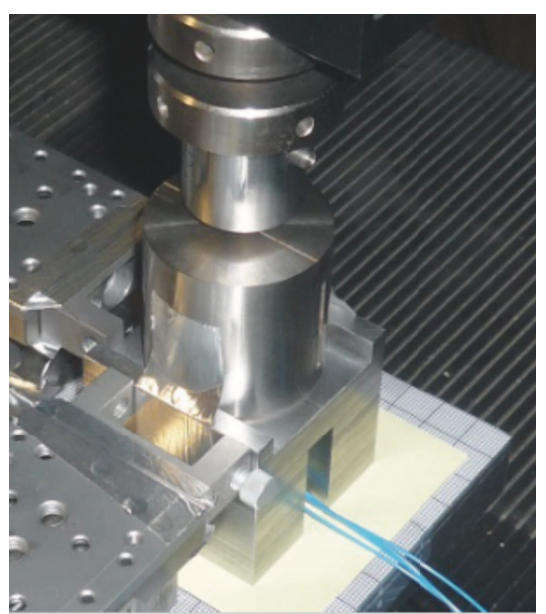

(a) Plug under press

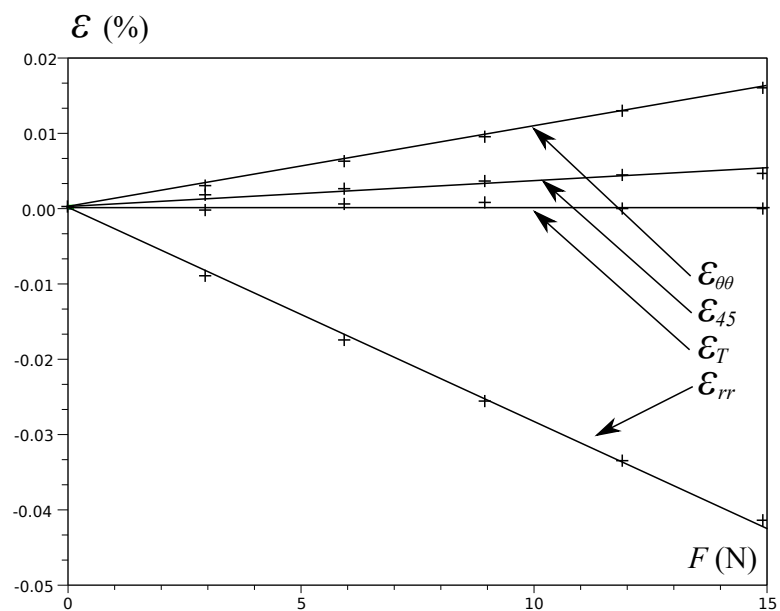

(b) Strain linearity $v s$. compression force

Figure 7: Testing FBGs response

The plug is inserted by compression at room temperature in a work roll hole that has been initially drilled (Figure 4a). To obtain a strong fixation of the plug in the roll, the difference of diameter between plug and hole is $1 \%$ (hole diameter smaller than plus diameter by $1 \%$ ). Once the plug has been inserted in the work roll, the surface is re-ground to be flat (Figure 8a) so that marks on strips are limited. After this roll re-grinding, the Bragg gratings are located at $2.175 \mathrm{~mm}$ under the roll surface.

Optical fibers signals are extracted from the roll center where all the four FBG reflected spectra are gathered together on a single optical fiber using an optical coupler. Thus all the four FBGs can be interrogated simultaneously. Bragg wavelength of each FBG has been determined with respect to the expected spectral range during the roll tests, in order to prevent two spectra to overlap, it is then still possible to identify each optical fiber even if, for any reason, only one reflected spectrum (instead of four expected) is transmitted through the optical coupler. This 
signal is then transmitted from the rotating roll to an external fixed data acquisition station through a Fiber Optic Rotary Joint (FORJ). One can see this rotary joint and the out-coming optical fiber in Figure 8b.

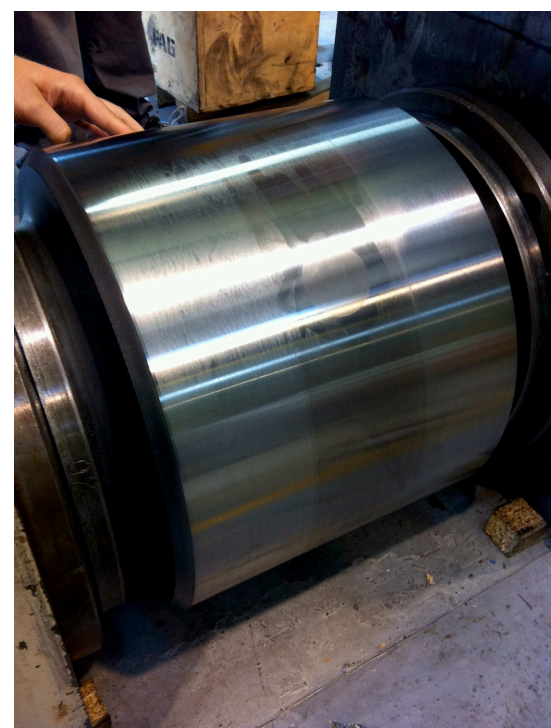

(a) Work roll with its instrumented plug

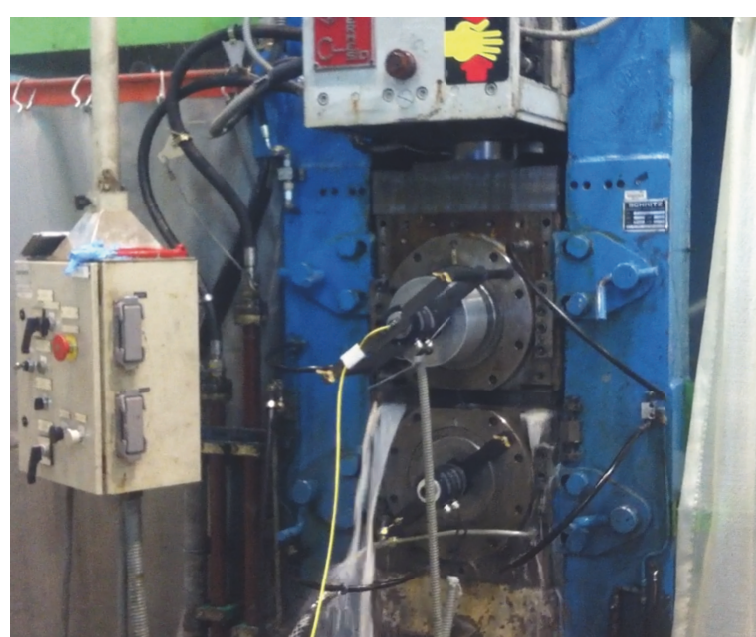

(b) Fiber Optic Rotary Joint installed in the instrumented work roll axis

Figure 8: Pictures of the work roll

\section{Sensor calibration}

The whole measurement system (composed of the work roll, the plug, the FBGs and the data acquisition system) has been calibrated with two different data acquisition systems working at two different frequencies: $960 \mathrm{~Hz}$ and $3378 \mathrm{~Hz}$. Both systems must be calibrated separately. To get calibration test conditions close to rolling conditions, the instrumented work roll is motorized and rotates directly against the other work roll that rotates freely (no motorization or brace) as shown in Figure 9a. No sliding between both rolls occurred during calibration tests, and shear stress in the roll/roll contact can be neglected because most of tangential forces applied in the contact are used to spin the lower roll and do not generate significant shear stress in the roll body. Thus, in these conditions, the classical Hertz contact formulas are applied in order to model calibration tests: Hertz formulas enable here to get a known contact stress distribution at roll surface to calibrate sub-surface optical fibers response. Three rolling forces, corresponding to 25 tons, 50 tons and 75 tons (or alternatively $833.3 \mathrm{~N} / \mathrm{mm}, 1666.6 \mathrm{~N} / \mathrm{mm}$ and $2500 \mathrm{~N} / \mathrm{mm}$ since the work roll width is $300 \mathrm{~mm}$ ) have been applied during calibration. However since linearity is good, as detailed in Section 3, all three tests have the same conclusions. The Hertz cylinder/cylinder contact formulas are summarized in Table 2, where the exponent $H$ refers to Hertz. Contact pressures for the three rolling forces are presented in Figure 9b. 


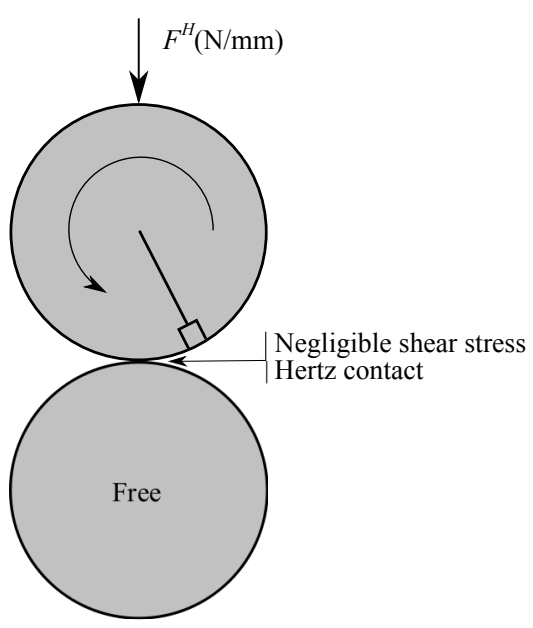

(a) Cylinder/cylinder

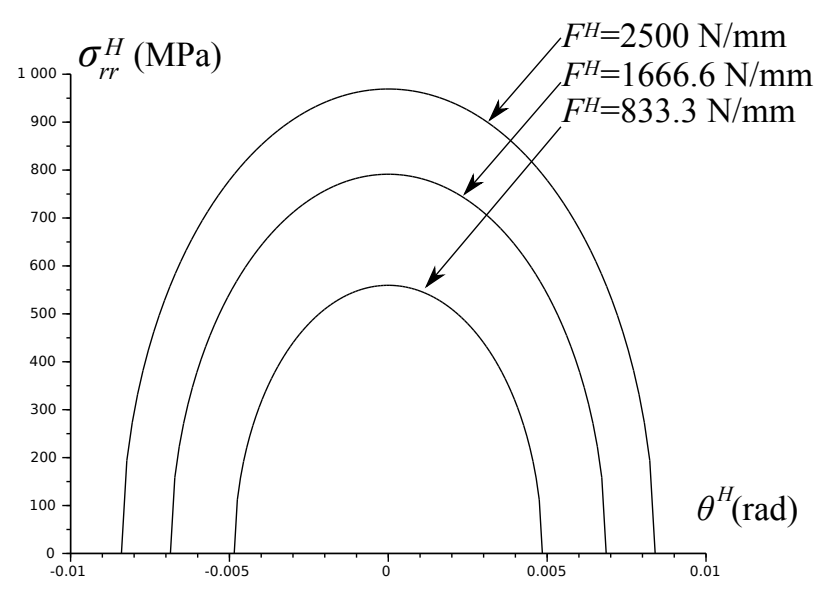

(b) Hertz contact pressures

Figure 9: Calibration test

Table 2: Hertz contact theory cylinder/cylinder

\begin{tabular}{|cc|c|c|}
\hline$F^{H}$ & $(\mathrm{~N} / \mathrm{mm})$ & Force per unit length & \\
\hline$l^{H}$ & $(\mathrm{~mm})$ & Contact length & $l^{H}=\sqrt{4 F^{H} R_{s} \frac{1-v^{2}}{E \pi}}$ \\
\hline$\theta^{H}$ & $(\mathrm{rad})$ & Contact angle & $\theta^{H} \in\left[-\frac{l^{H}}{R_{s}}, \frac{l^{H}}{R_{s}}\right]$ \\
\hline$\sigma^{H}$ & $(\mathrm{MPa})$ & Contact pressure & $\sigma_{r r}^{H}=\frac{2 F^{H}}{\pi\left(l^{H}\right)^{2}} \sqrt{\left(l^{H}\right)^{2}-R_{s}^{2} \theta^{H}}$ \\
\hline
\end{tabular}

With the Hertz contact pressure $\sigma^{H}$, a very simple elastic model enables to compute strains in the roll body and especially at the inner radius $R_{m}$. Multiplicative calibration coefficients $K_{45}, K_{\theta \theta}$ and $K_{r r}$ are obtained by matching computed strains (at the inner radius $R_{m}$ ) with measured strains. Matching process is done by minimizing the relative error. The computed calibration coefficients are listed in Table 3 . It should also be mentioned that measured signals are not perfectly synchronized with computed strains at the inner radius $R_{m}$. There is a slight time difference between measured strains $\varepsilon_{45}^{m}$ and $\varepsilon_{\theta \theta}^{m}$. This is likely due to cumulative effects of a slight mispositioning of the circumferential Optical Fiber, that may have not been glued perfectly at the bottom of the hole, and a slight misalignment during the insertion of the plug inside the roll. Thus, FBGs (circumferential and at 45 degrees) are not perfectly aligned along the axial direction and do not enter the roll gap simultaneously as shown in Figure 10. Calibration tests enable to quantify this misalignment and $d_{\text {miss }} \simeq 1.74 \mathrm{~mm}$ where $d_{\text {miss }}$ denotes the distance along the circumferential direction between FBGs measuring $\varepsilon_{45}^{m}$ and $\varepsilon_{\theta \theta}^{m}$. Therefore measured signals can be shifted in order to correct this misalignment and obtain a good overlap between computations and measurements. 


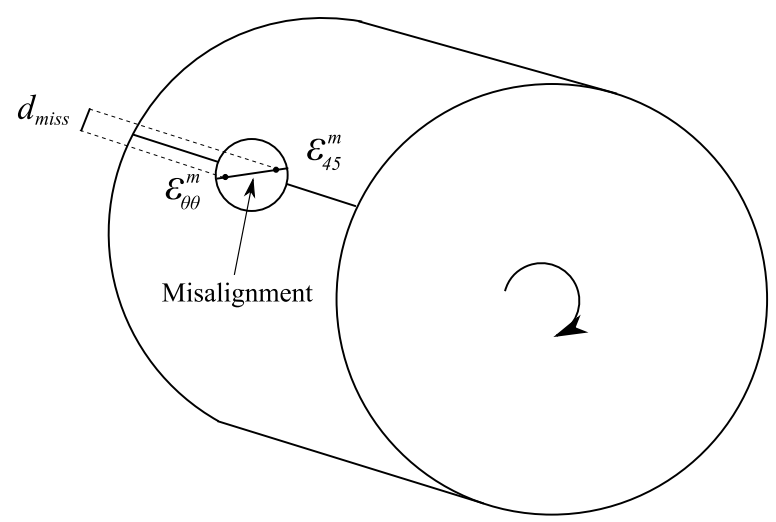

Figure 10: Mispositioning of the circumferential Optical Fiber and plug misalignment once inserted into the work roll

The comparison between direct computations and measurements for the test at 75 tons is presented in Figure 11 for the data acquisition station at $3378 \mathrm{~Hz}$ (very similar results are obtained for 25 tons and 50 tons and for the other data acquisition station). It is clear that $\varepsilon_{45}^{m}$ and $\varepsilon_{\theta \theta}^{m}$ are consistent and well calibrated, the strain peak is accurate and very good overlap between computations and measurements is obtained after shifting one signal in order to correct the misalignment of the plug. However $\varepsilon_{r r}^{m}$ obviously presents a lack of trueness (Joint Committee for Guides in Metrology (2012)) because the peak spreads on a much larger angular zone than expected. Probably, this FBG is not perfectly glued at its expected position in the hole, or residual air voids in the vicinity of the FBG compromise measurements, but other explanations are still possible. Most of the time, when inconsistent data are measured, the inverse interpretation needs a projection of the inconsistent inputs on the set of consistent data. In the presented experimental tests, it has been considered simpler to remove the signal $\varepsilon_{r r}^{m}$ from the inputs because the simple adaptation of the inverse method proposed by Weisz-Patrault et al. (2011) presented in Section 2 was available. The radial signal $\varepsilon_{r r}^{m}$ is not used in the following.

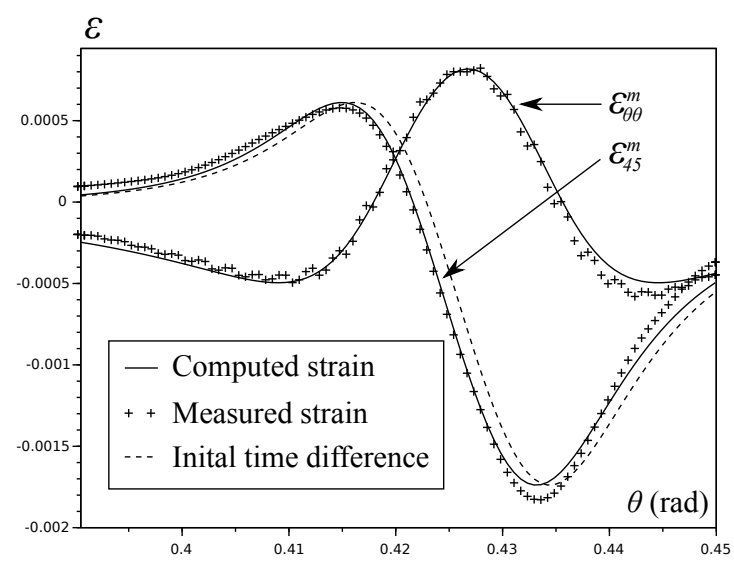

(a) Calibration: $\varepsilon_{\theta \theta}^{m}$ and $\varepsilon_{45}^{m}$

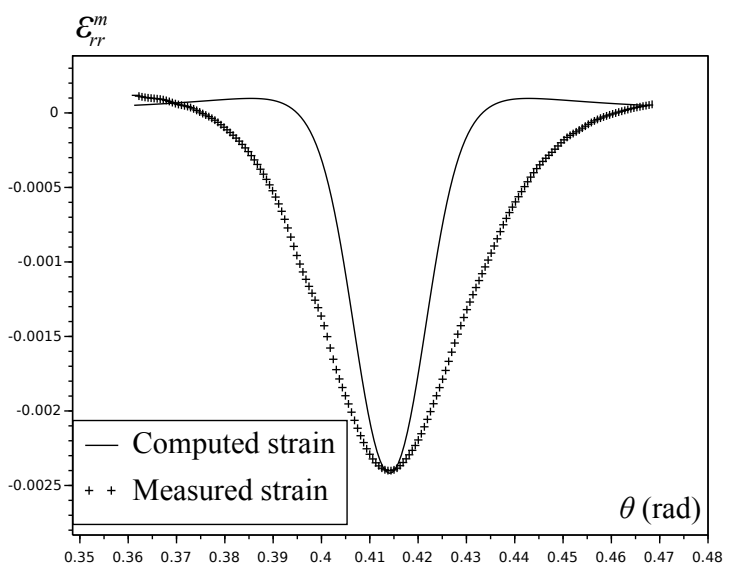

(b) Calibration: $\varepsilon_{r r}^{m}$

Figure 11: Calibration results

Table 3: Calibration coefficients

\begin{tabular}{|c|c|c|}
\hline calibration coefficient & Data acquisition station $(960 \mathrm{~Hz})$ & Data acquisition station $(3378 \mathrm{~Hz})$ \\
\hline$K_{45}$ & 4.7 & 1.44 \\
\hline$K_{\theta \theta}$ & 1.4 & 0.96 \\
\hline$K_{r r}$ & - & - \\
\hline
\end{tabular}




\section{Pilot rolling tests}

Several tests have been performed at the ArcelorMittal research center at Maizières-lès-Metz on a cold pilot rolling mill. For all tests, strips of low carbon steel grade (thickness $=2.8 \mathrm{~mm}$ ) and strips of aluminium killed grade (thickness $=0.75 \mathrm{~mm}$ ) and hardened by an initial cold rolling reduction have been used and lubrication was made by emulsion. During trials various rolling speeds, strip exit tensions and thickness reduction ratios were tested. Comparisons between measurement inverse calculation and LAM3 numerical simulations (Hacquin (1996)) are proposed. The geometrical and material parameters for all different tests are listed in Table 4. It should be noted that thermal conditions are very homogeneous and thermal compensation is negligible for these isothermal tests. However, thermal compensation will be necessary for different rolling conditions, even though this paper focuses on isothermal interpretation. Further investigations have to focus on hot rolling conditions with thermal compensation, and an inverse method using a thermo-elastic coupling as developed by Weisz-Patrault et al. (2013a).

Table 4: Geometrical and material parameters

\begin{tabular}{|ll|l|l|}
\hline$R_{s}$ & $(\mathrm{~mm})$ & 195.5 & Outer radius \\
\hline$R_{m}$ & $(\mathrm{~mm})$ & 193.325 & Inner radius \\
\hline$d$ & $(\mathrm{~mm})$ & 2.175 & Depth \\
\hline$E$ & $(\mathrm{MPa})$ & 210000 & Young modulus \\
\hline$v$ & $(-)$ & 0.3 & Poisson ratio \\
\hline$L$ & $(\mathrm{~mm})$ & 300 & Roll width \\
\hline$l$ & $(\mathrm{~mm})$ & 100 & Strip width \\
\hline
\end{tabular}

\subsection{Influence of rolling speeds}

Various rotation speeds are tested under similar cold rolling conditions. Rolling parameters are listed in Table 6, and tests are summarized in Table 5. Rotation speeds are set from very slow experimental conditions (strip speed: $25 \mathrm{~m} / \mathrm{min}$ ) to semi-industrial conditions (strip speed: $400 \mathrm{~m} / \mathrm{min}$ ). Rolling forces are relatively similar (from $6220 \mathrm{~N} / \mathrm{mm}$ to $7200 \mathrm{~N} / \mathrm{mm}$ ). These tests aim at demonstrating the applicability of the inverse method with the detailed experimental apparatus in high speed industrial conditions, with rotation speeds around $70 \mathrm{rad} / \mathrm{s}$ corresponding to $800 \mathrm{~m} / \mathrm{min}$ strip speed. Therefore, data acquisition frequency is a key point for relevant measurement interpretation. In this section the data acquisition system with the higher frequency $f=3378 \mathrm{~Hz}$ is used.

Table 5: Tests summary

\begin{tabular}{|c|c|c|c|}
\hline Test & Strip speed $(\mathrm{m} / \mathrm{min})$ & Rotation speed $\omega(\mathrm{rad} / \mathrm{s})$ & Rolling force $F_{R}(\mathrm{~N} / \mathrm{mm})$ \\
\hline 1 & 25 & 2.13 & 6220 \\
\hline 2 & 50 & 4.26 & 6430 \\
\hline 3 & 100 & 8.53 & 6660 \\
\hline 4 & 300 & 25.58 & 7050 \\
\hline 5 & 400 & 34.00 & 7200 \\
\hline
\end{tabular}

Table 6: Rolling parameters

\begin{tabular}{|ll|l|l|}
\hline$f$ & $(\mathrm{~Hz})$ & 3378 & Data acquisition frequency \\
\hline$t_{0}$ & $(\mathrm{~mm})$ & 2.8 & Strip entry thickness \\
\hline$t_{1}$ & $(\mathrm{~mm})$ & 2.154 & Strip exit thickness \\
\hline$T$ & $(\%)$ & 30 & Thickness reduction ratio \\
\hline$\sigma_{0}^{T}$ & $(\mathrm{MPa})$ & 39.4 & Strip entry tension \\
\hline$\sigma_{1}^{T}$ & $(\mathrm{MPa})$ & 117.5 & Strip exit tension \\
\hline$l_{C}$ & $(\mathrm{~mm})$ & $\simeq 14$ & Contact length \\
\hline
\end{tabular}

Measured strains for four cycles are presented in the contact vicinity for test 1 and test 5 in Figure 12. Reproducibility is excellent from one cycle to another (similar figures are obtained for tests 2, 3 and 4). Detailed measured signals in the contact vicinity are presented in Figure 13 for the first cycle. Of course the number of 
measurement points and the time interval under the contact decreases when the rotation speed increases. Although represented in Figure 13, radial strain $\varepsilon_{r r}^{m}$ is not used in this paper. Measurement noise is limited. In addition, all the relevant information is located in the contact vicinity, thus measured signals are cleaned by applying a filtering window that selects strain variations only near the contact.

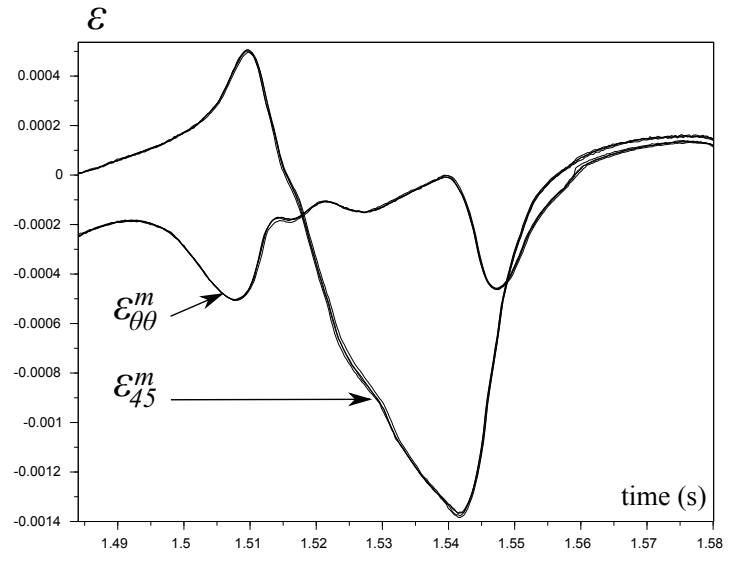

(a) Test 1: measured $\varepsilon_{45}^{m}$ and $\varepsilon_{\theta \theta}^{m}$

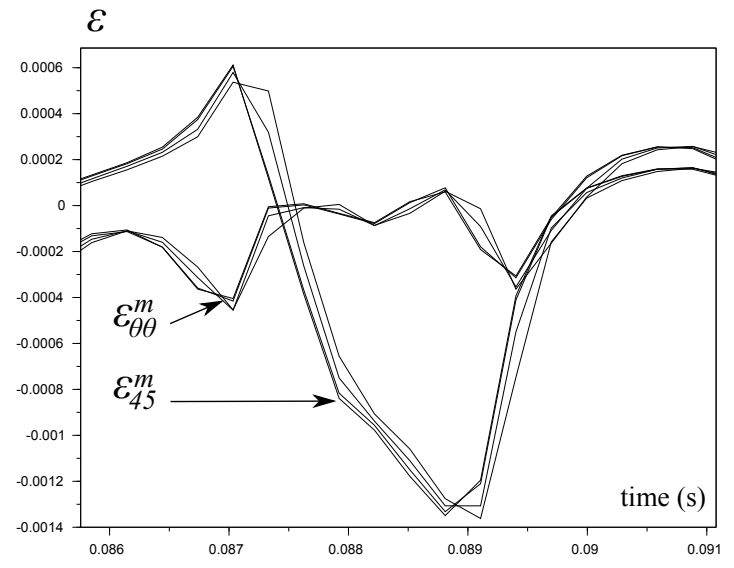

(b) Test 5: measured $\varepsilon_{45}^{m}$ and $\varepsilon_{\theta \theta}^{m}$

Figure 12: Measurements overlapping during 4 cycles 
$\varepsilon$

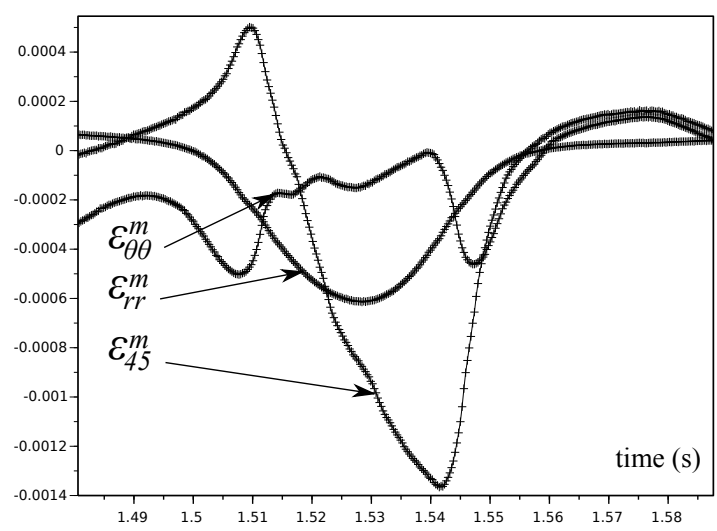

(a) Test 1: measured $\varepsilon_{45}^{m}, \varepsilon_{\theta \theta}^{m}$ and $\varepsilon_{r r}^{m}$

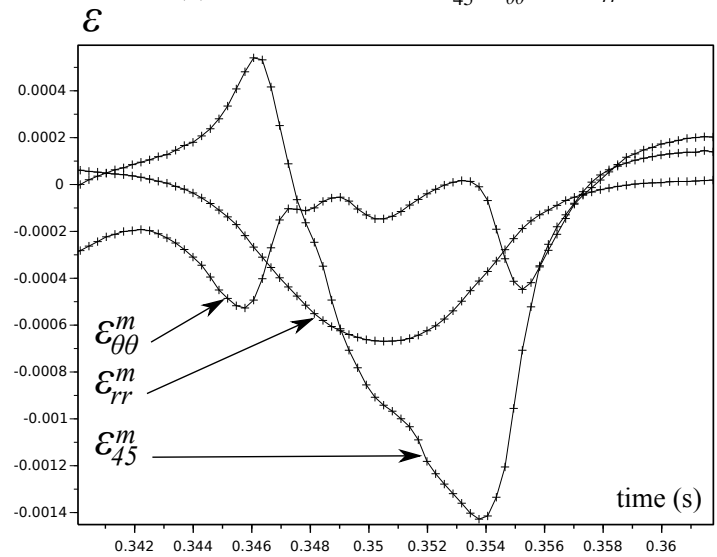

(c) Test 3: measured $\varepsilon_{45}^{m}, \varepsilon_{\theta \theta}^{m}$ and $\varepsilon_{r r}^{m}$

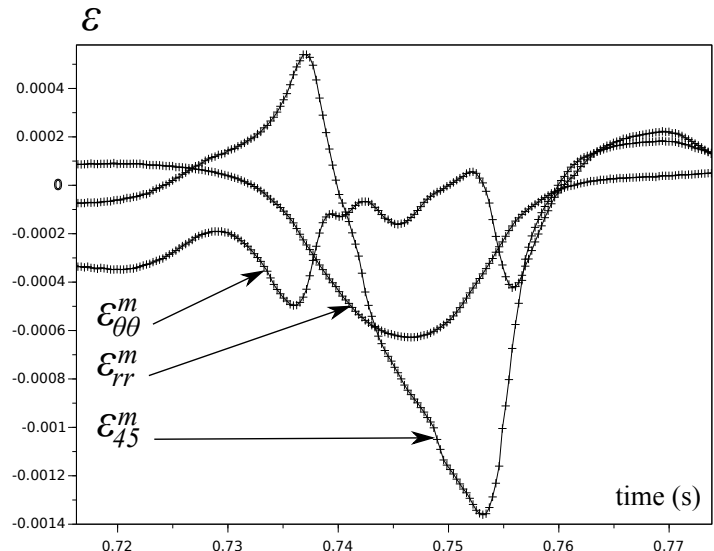

(b) Test 2: measured $\varepsilon_{45}^{m}, \varepsilon_{\theta \theta}^{m}$ and $\varepsilon_{r r}^{m}$

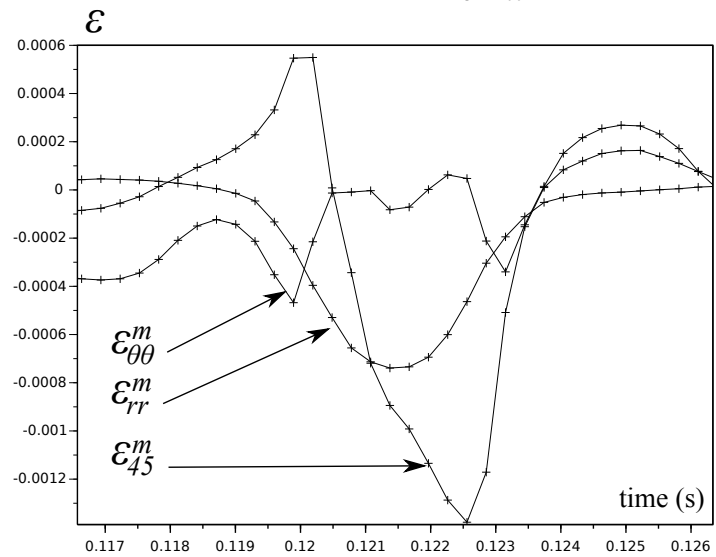

(d) Test 4: measured $\varepsilon_{45}^{m}, \varepsilon_{\theta \theta}^{m}$ and $\varepsilon_{r r}^{m}$

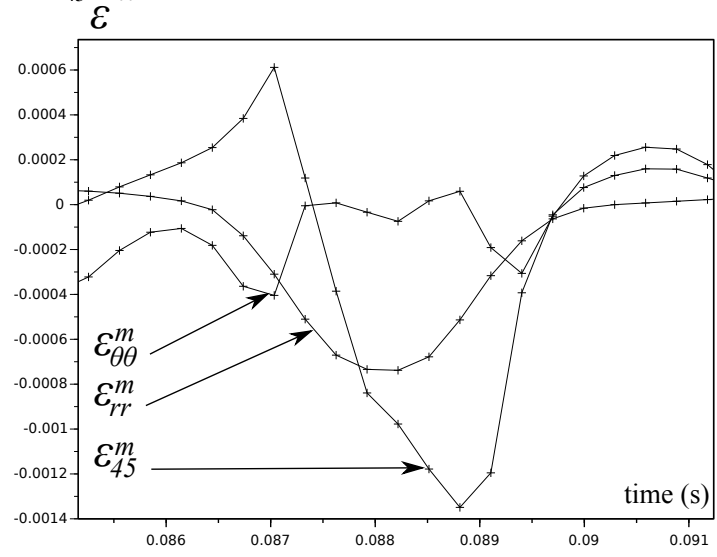

(e) Test 5: measured $\varepsilon_{45}^{m}, \varepsilon_{\theta \theta}^{m}$ and $\varepsilon_{r r}^{m}$

Figure 13: Detailed measured deformations 

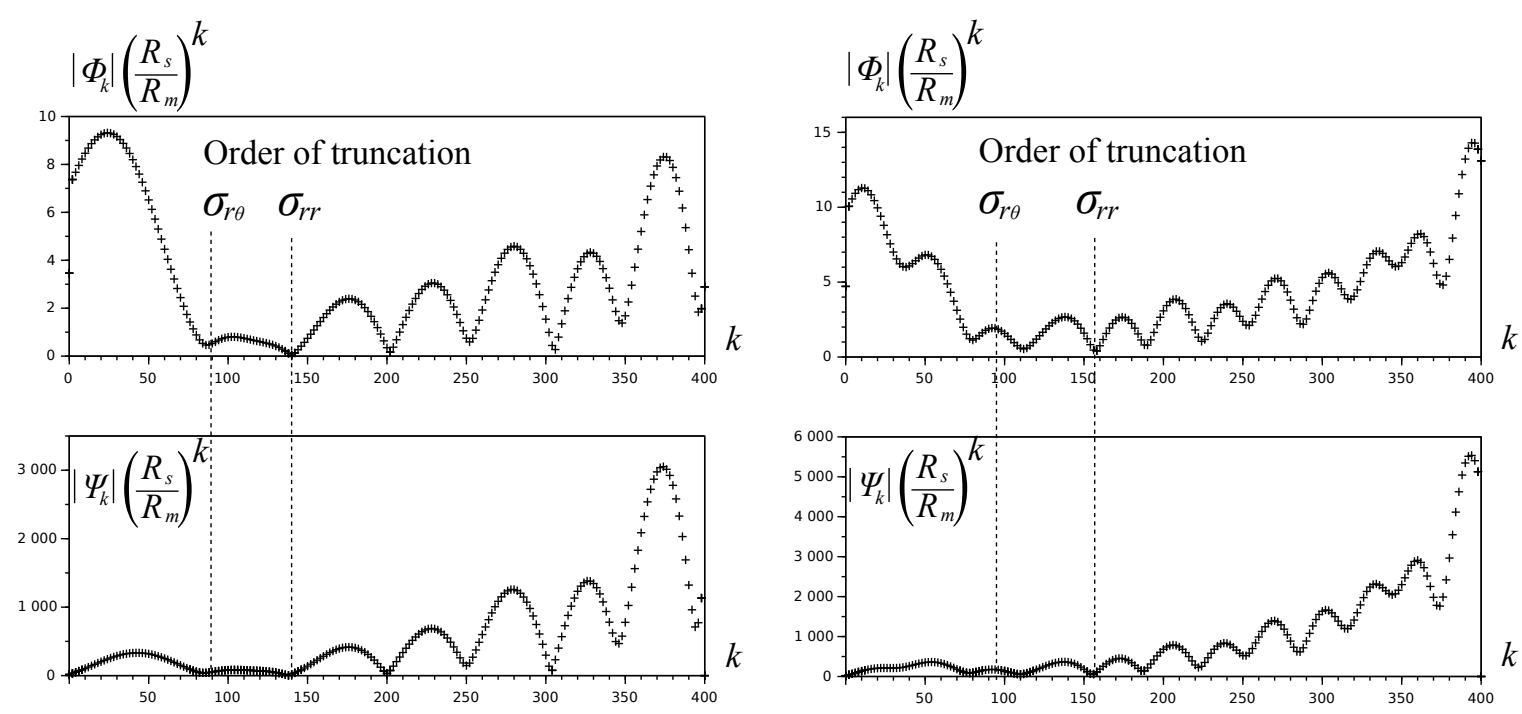

(a) Test 1: amplification factors

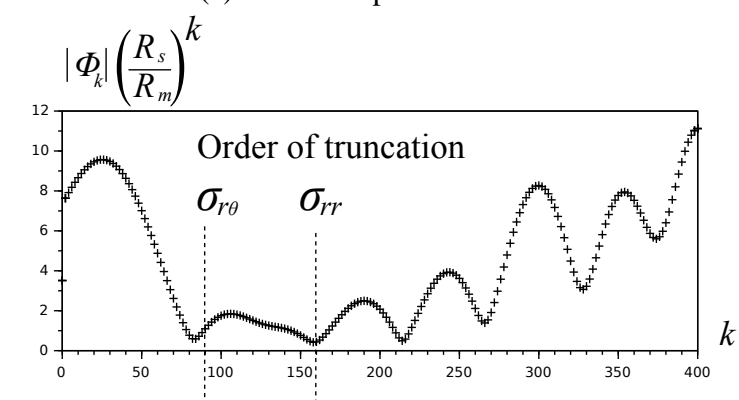

(b) Test 2: amplification factors

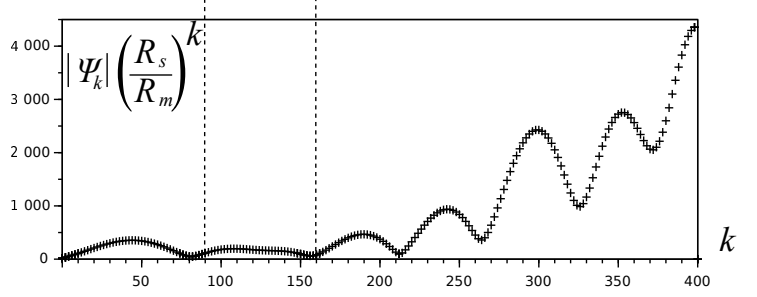

(c) Test 3: amplification factors

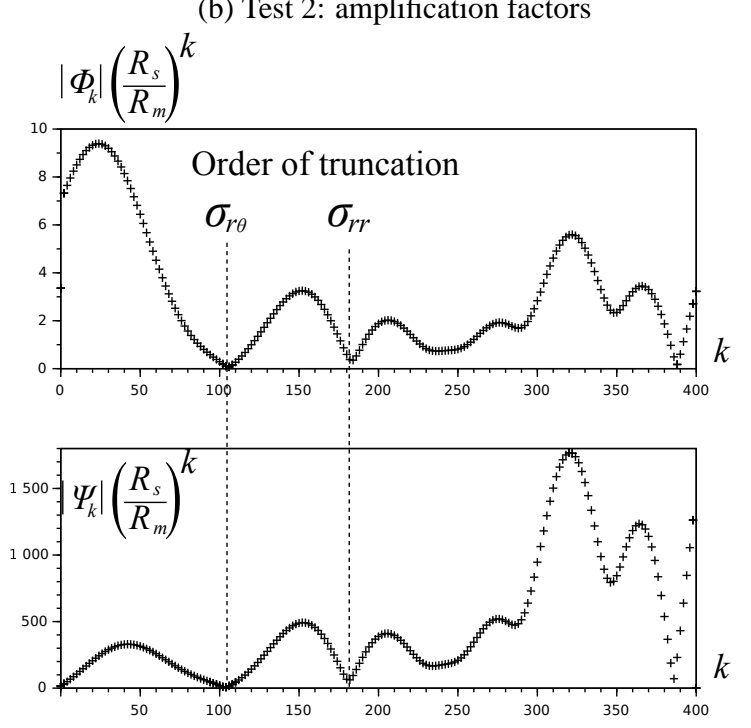

(d) Test 4: amplification factors

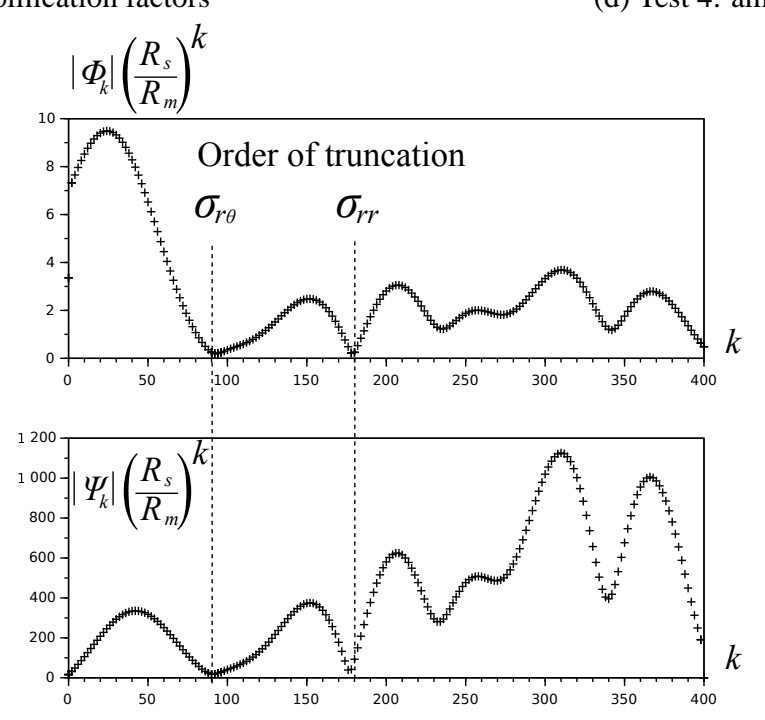

(e) Test 5: amplification factors

Figure 14: Amplification factors and ill-posedness 
Then, the inverse method presented in this paper is applied in order to evaluate stresses at the roll surface and especially along the roll-strip contact length. The regularization of the inverse method is obtained by truncating the infinite sums involved in (6), by plotting the amplification factors $\left|\Phi_{k}\right|\left(R_{s} / R_{m}\right)^{k}$ and $\left|\Psi_{k}\right|\left(R_{s} / R_{m}\right)^{k}$ that determine the ill-posedness of the inverse method (i.e., instability due to small errors on the inputs leading to large errors on the outputs) as shown in Figure 14. It should be noted that the amplitude of normal contact stress is much larger than the amplitude of contact shear stress. Therefore, experimental errors done on coefficients $\Phi_{k}$ and $\Psi_{k}$ (used for both normal and shear stresses) are more critical for the evaluation of shear stress than for normal stress. Thus, the order of truncation determined for the regularization of the inverse method is smaller for shear stress than for normal stress. It should be noted that in this work the automatic procedure of the truncation process has not been used and should be developed for future industrial applications.

Since the inverse method is based on truncated sums, it is logical to obtain unwanted large oscillations just before and after the stress peak (alike the reconstruction with Fourier series of a rectangular signal). However, this classical issue is overcome by applying a filtering window in order to focus on contact stresses only. The contact length $l_{C}$ is evaluated by using the strip entry and exit thicknesses $t_{0}$ and $t_{1}$, the rolling force and the approximate deformed roll radius as established classically by Hitchcock (1935). Thus, the filtering window is set such as the contact is selected. Contact stresses presented in Figures 15 and 16 are evaluated with the inverse method developed in this paper and the measured strains presented in Figure 13. Very classical peak of pressure $\sigma_{r r}\left(R_{s}, \theta\right)$ and sign change of shear stress $\sigma_{r \theta}\left(R_{s}, \theta\right)$ are obtained in the roll gap. Amplitudes of shear stress and contact pressure do not have the same order of magnitude along the contact length, which was predicted by numerical simulations. Furthermore, the high-speed data acquisition frequency enables the evaluation of contact stresses at semi-industrial rolling speeds (test 5) without any significant quality loss. The shear stress reconstruction is somewhat a bit poorly reconstructed compared to normal stress, due to insufficient number of harmonics used for reconstruction; however this difficulty may be overcome by increasing the acquisition frequency of Optical Fibers and by correcting the radial strain measurement issue. Present results are anyway promising for future adaptation on high speed industrial mills. Pilot tests presented in this Section can be modeled numerically using the software LAM3 based on Hacquin (1996) as mentioned in the introduction. The strip is modeled by FEM with elasto-visco-plastic behavior and the roll remains elastic. The coupling between strip and roll deformations are taken into account as well as rolling force, rotation speed, entry and exit tension applied to the strip, entry and exit thicknesses etc... The outputs are, amongst others, the simulated contact stresses. Rolling conditions of test 2 are modeled with LAM3 and contact stresses are extracted and compared with the experimental evaluations based on the inverse method and the experimental apparatus detailed in this paper. Since all tests from 1 to 5 are very similar (apart from rotation speeds), all tests are compared with this single numerical simulation. Good agreement is obtained as shown in Figures 15 and 16. It can be noticed that contact shear stress have the right order of magnitude, however the simulated discontinuity of shear stress due to a Coulomb friction law is not evaluated with the inverse method interpreting strain measurements. This is due to the fact that the order of truncation (as presented in Figure 14) cannot be set sufficiently large (because of ill-posedness), thus sharp discontinuities like shear stress near the neutral point cannot be reproduced properly. Indeed Weisz-Patrault et al. (2011) demonstrated for a very common cold rolling condition that around 500 terms are needed for a good evaluation by inverse method (study without measurement noise), whereas only around 100 terms are considered in the present study. 


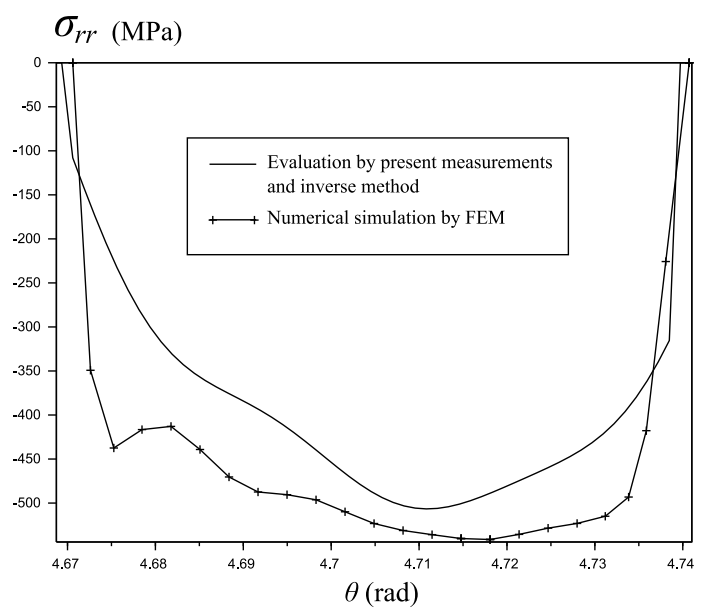

(a) Test 1: evaluation of contact pressure $\sigma_{r r}(\mathrm{MPa})$

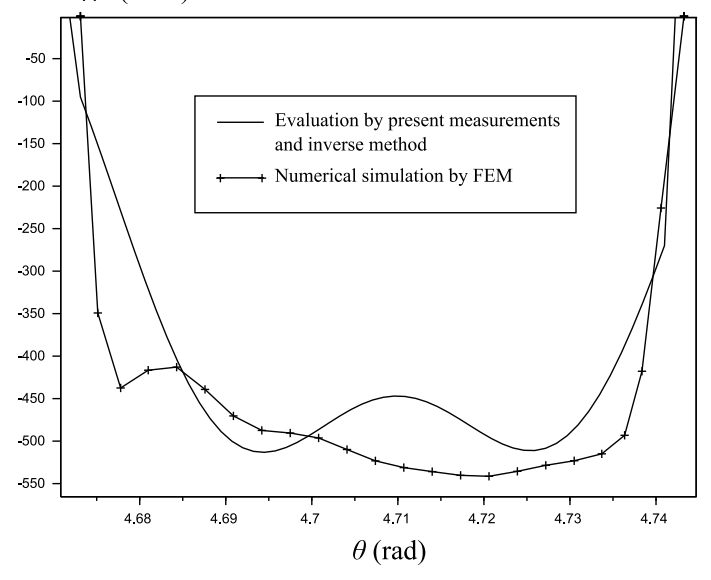

(c) Test 3: evaluation of contact pressure

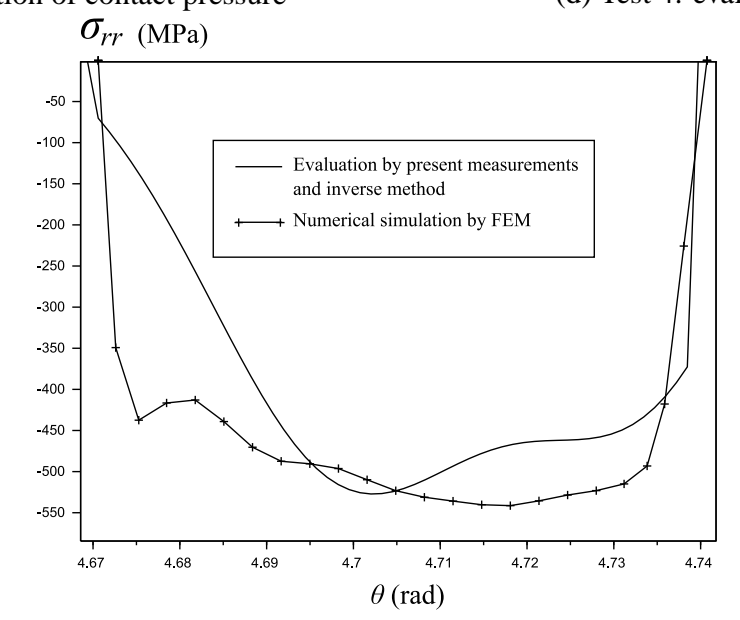

(e) Test 5: evaluation of contact pressure

Figure 15: Evaluation of contact pressure by inverse method and comparison with numerical simulation

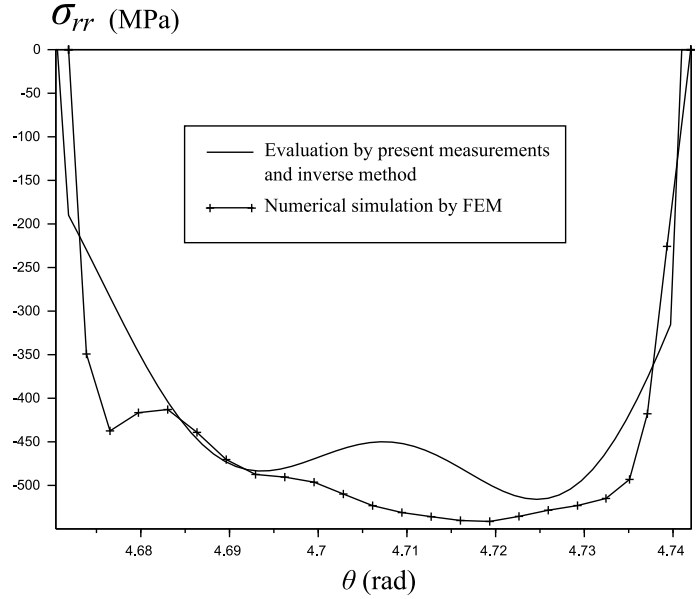

(b) Test 2: evaluation of contact pressure

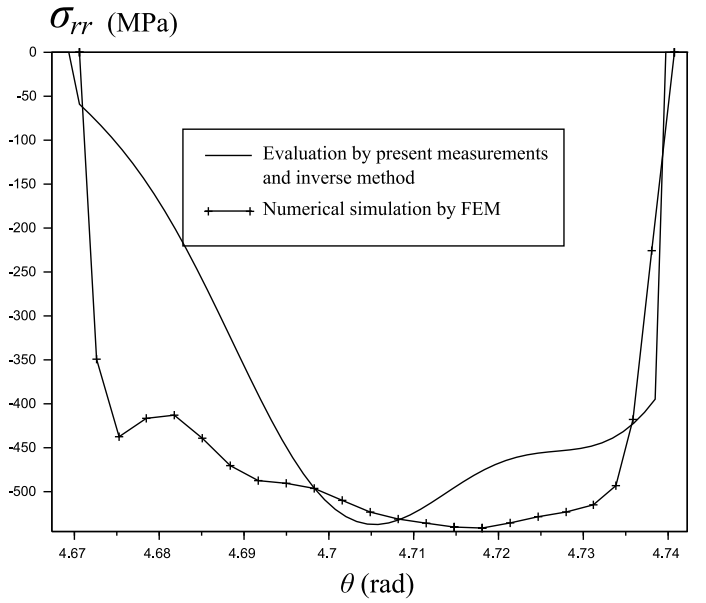

(d) Test 4: evaluation of contact pressure 


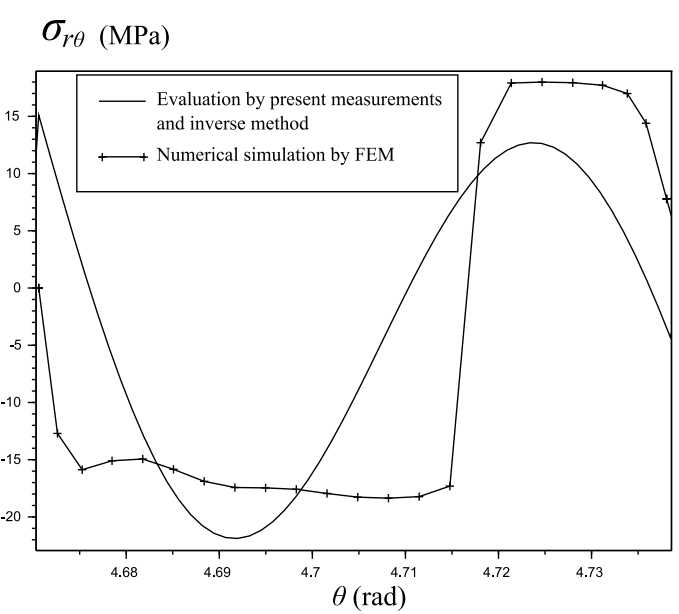

(a) Test 1: evaluation of contact shear stress

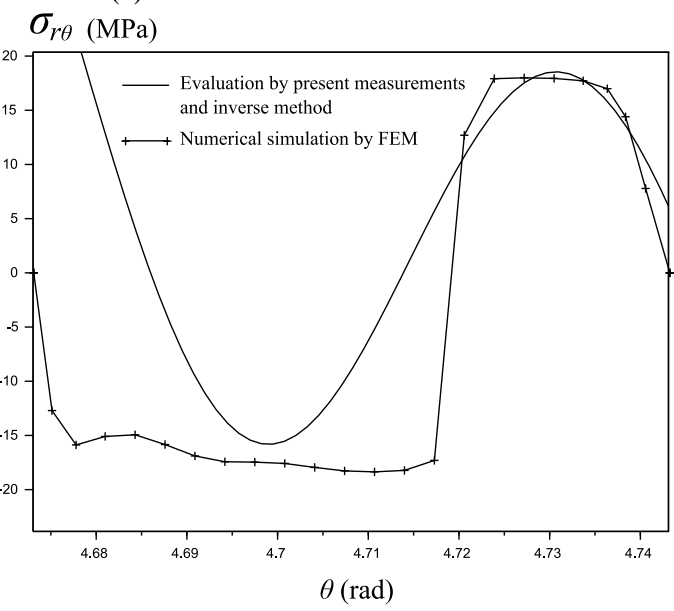

(c) Test 3: evaluation of contact shear stress

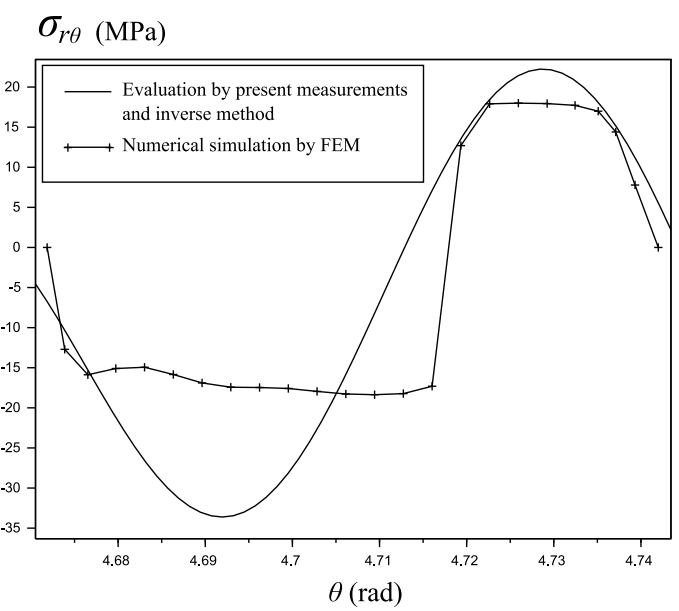

(b) Test 2: evaluation of contact shear stress $\sigma_{r \theta}(\mathrm{MPa})$

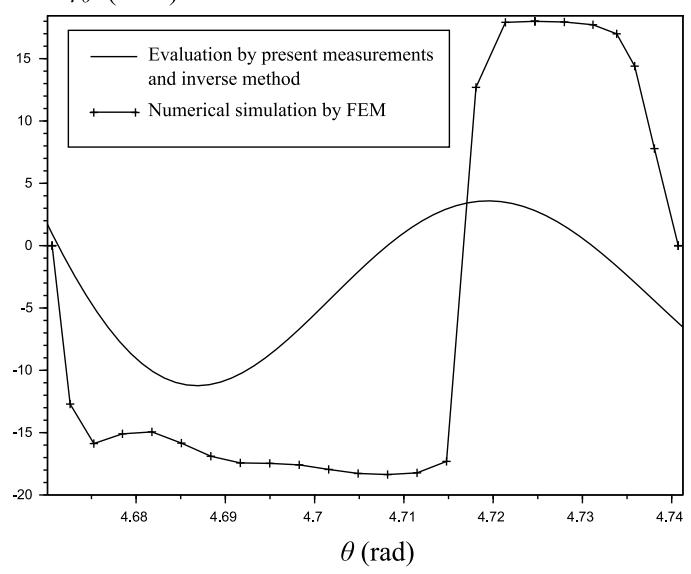

(d) Test 4: evaluation of contact shear stress

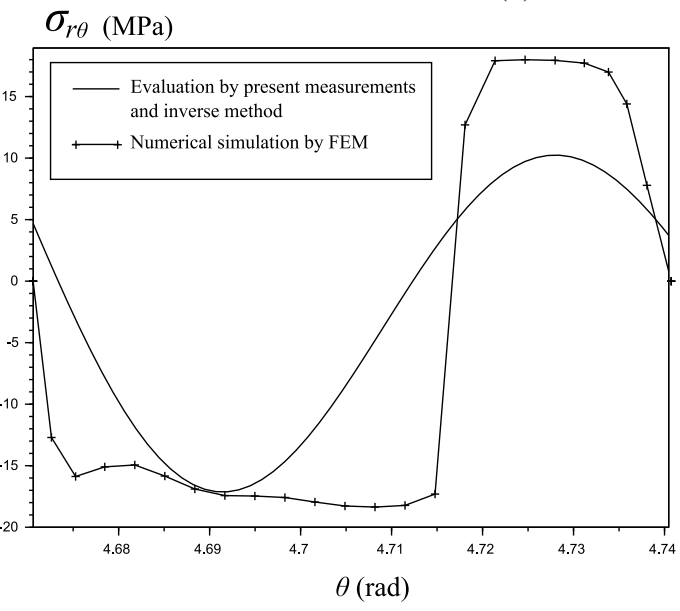

(e) Test 5: evaluation of contact shear stress

Figure 16: Evaluation of contact shear stress by inverse method and comparison with numerical simulation

\subsection{Influence of strip exit tension}

The influence of strip exit tension is investigated in this section. Two cold rolling tests have been performed with same rolling parameters but the strip exit tension as listed in Tables 7 and 8. Much thinner strips are rolled for these tests than for test from 1 to 5 . The acquisition system working at $960 \mathrm{~Hz}$ has been used. Details of measurements are presented in Figure 17. Amplification coefficients and truncation orders are given in Figure 18. 
Both tests 6 and 7 are simulated numerically using LAM3 Hacquin (1996). The metal flow is constant in the roll gap, thus the strip speed is higher at the exit of the contact length than at its entry. Thus, the relative speed between strip and roll and so the shear stress present a characteristic sign change in the contact. The neutral point is defined as the position where shear stress sign changes along the contact length. When the exit tension increases (and the entry tension remains constant), there is a shift of the neutral point towards the entry of the contact. This usual behavior is due to the fact that the difference between the entry and exit applied forces corresponds to the resultant tangential force in the contact length that decreases when the exit applied tension increases. Numerical simulations of both tests 6 and 7 are compared with the experimental evaluation based on the present inverse method as shown in Figure 19. Reasonable agreement is obtained for pressure, however as explained in the previous section, shear stress does not reproduce the classical discontinuity at the neutral point. Even though the neutral point shift (when the exit applied tension increases) is evaluated with the inverse method, contact shear stress is not sufficiently accurate to give a reliable experimental evidence. As mentioned above, this limitation is mainly due to a too low truncation order (i.e. high regularization level of the inverse method).

Table 7: Tests summary

\begin{tabular}{|c|c|c|}
\hline Test & Strip exit thickness $t_{1}(\mathrm{~mm})$ & Strip exit tension $\sigma_{1}^{T}(\mathrm{MPa})$ \\
\hline 6 & 0.643 & 184.7 \\
\hline 7 & 0.619 & 265.2 \\
\hline
\end{tabular}

Table 8: Rolling parameters for tests 6 and 7

\begin{tabular}{|ll|l|l|}
\hline$f$ & $(\mathrm{~Hz})$ & 960 & Frequency of acquisition \\
\hline$t_{0}$ & $(\mathrm{~mm})$ & 0.75 & Strip entry thickness \\
\hline$\sigma_{0}^{T}$ & $(\mathrm{MPa})$ & 117.72 & Strip entry tension \\
\hline$l_{C}$ & $(\mathrm{~mm})$ & $\simeq 7$ & Contact length \\
\hline$F_{R}$ & $(\mathrm{~N} / \mathrm{mm})$ & 5831 & Rolling force \\
\hline$\omega$ & $(\mathrm{rad} / \mathrm{s})$ & 4.26 & Rotation speed \\
\hline
\end{tabular}

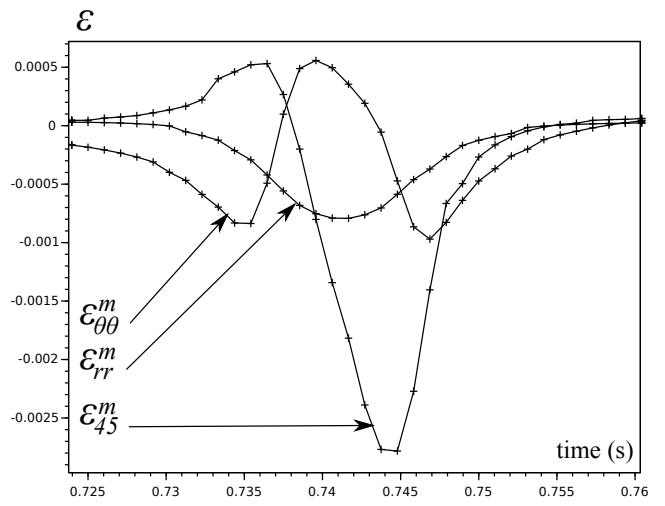

(a) Test 6: measured $\varepsilon_{45}^{m}, \varepsilon_{\theta \theta}^{m}$ and $\varepsilon_{r r}^{m}$

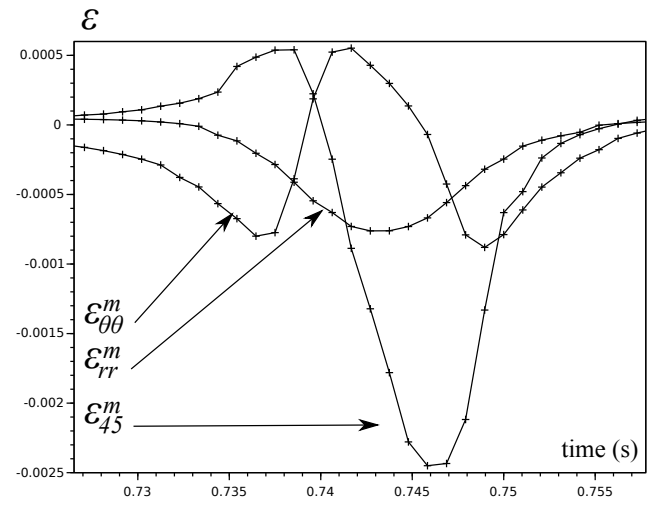

(b) Test 7: measured $\varepsilon_{45}^{m}, \varepsilon_{\theta \theta}^{m}$ and $\varepsilon_{r r}^{m}$

Figure 17: Detailed measured deformations 

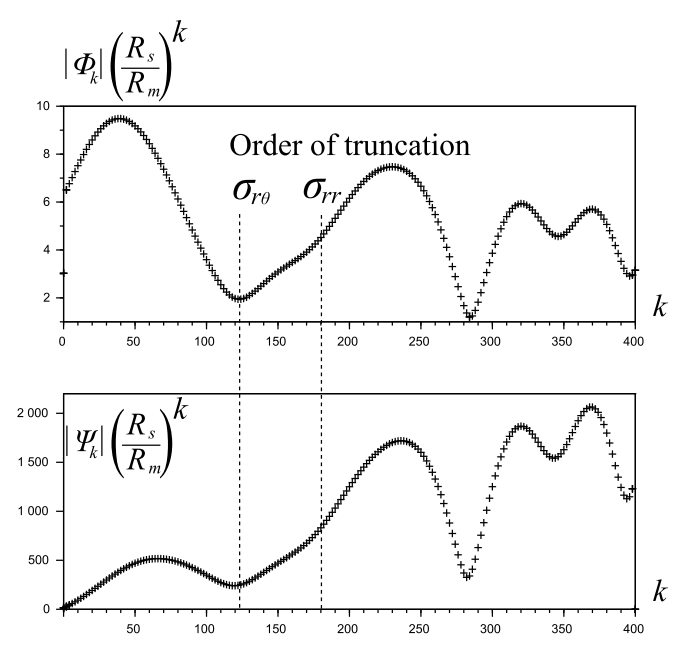

(a) Test 6: amplification factors

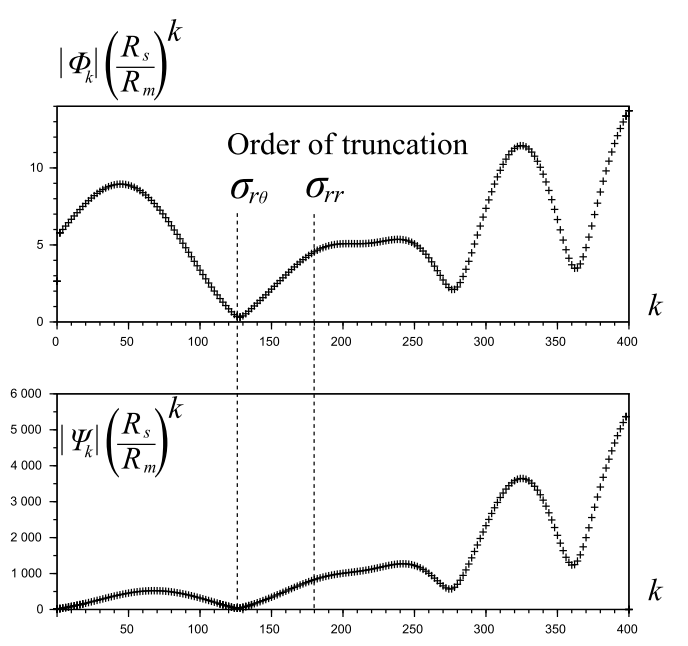

(b) Test 7: amplification factors

Figure 18: Amplification factors and ill-posedness

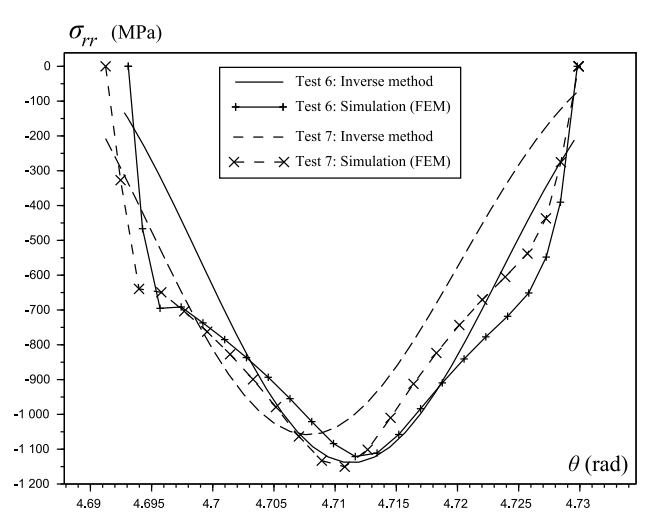

(a) Test 6 and 7: contact pressure

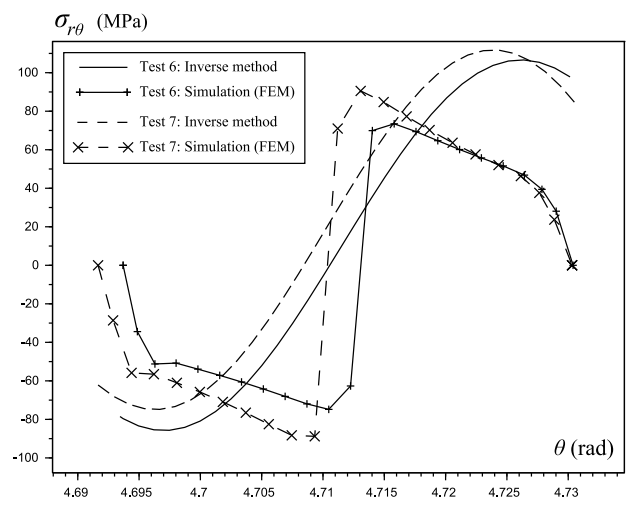

(b) Test 6 and 7: contact shear stress

Figure 19: Evaluation of contact stress by inverse method and comparison with numerical simulation

\subsection{Influence of thickness reduction ratio}

Two additional cold rolling tests are presented in order to show the influence of the thickness reduction ratio (from $10 \%$ for test 8 to $80 \%$ for test 9 ). Thin strips are rolled alike tests 6 and 7 and rolling parameters are presented in Tables 9 and 10. Unfortunately, these tests have been performed with the acquisition station at $960 \mathrm{~Hz}$. Thus, for test 8 with short contact length $(6.25 \mathrm{~mm})$ very few measurement points are recorded in the contact vicinity as shown in Figure 20. Then amplification coefficients are presented in Figure 21 and resulting evaluation of contact stress is presented in Figures 22 and 23. Alike for others tests, numerical simulations have been performed using the Finite Element model developed by Hacquin (1996). Good agreement is observed for pressure and an approximate order of magnitude is obtained for shear stress for test $9\left(T_{R}=80 \%\right)$. However it should be mentioned that shear stress cannot be evaluated by inverse method for test $8\left(T_{R}=10 \%\right)$, likely because there is too few measurement points in the contact vicinity.

Table 9: Tests summary

\begin{tabular}{|c|c|c|c|c|c|}
\hline Test & $t_{0}(\mathrm{~mm})$ & $t_{1}(\mathrm{~mm})$ & $T_{R}(\%)$ & $F_{R}(\mathrm{~N} / \mathrm{mm})$ & $l_{C}(\mathrm{~mm})$ \\
\hline 8 & 0.75 & 0.682 & 10 & 5011 & 6.25 \\
\hline 9 & 0.75 & 0.417 & 80 & 11684 & 11.4 \\
\hline
\end{tabular}


Table 10: Rolling parameters for tests 8 and 9

\begin{tabular}{|ll|l|l|}
\hline$f$ & $(\mathrm{~Hz})$ & 960 & Frequency of acquisition \\
\hline$\sigma_{0}^{T}$ & $(\mathrm{MPa})$ & 117.72 & Strip entry tension \\
\hline$\sigma_{1}^{T}$ & $(\mathrm{MPa})$ & 186.4 & Strip exit tension \\
\hline$\omega$ & $(\mathrm{rad} / \mathrm{s})$ & 4.26 & Rotation speed \\
\hline
\end{tabular}

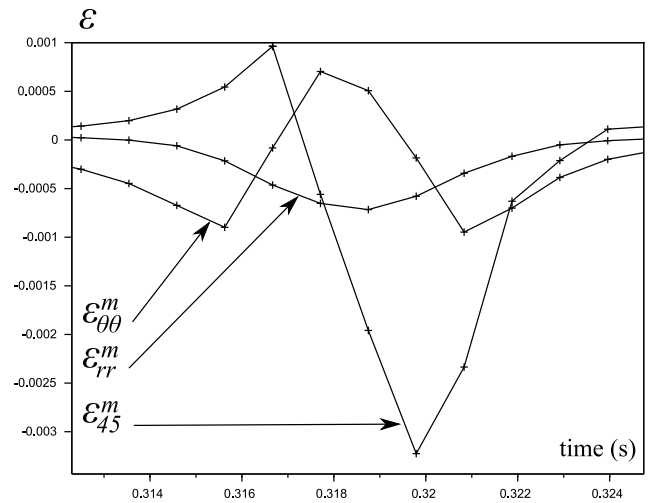

(a) Test 8: measured $\varepsilon_{45}^{m}, \varepsilon_{\theta \theta}^{m}$ and $\varepsilon_{r r}^{m}$

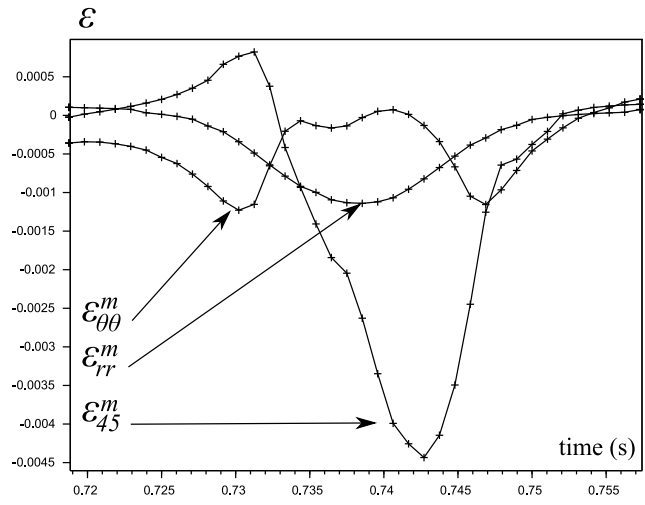

(b) Test 9: measured $\varepsilon_{45}^{m}, \varepsilon_{\theta \theta}^{m}$ and $\varepsilon_{r r}^{m}$

Figure 20: Zoom of measured deformations

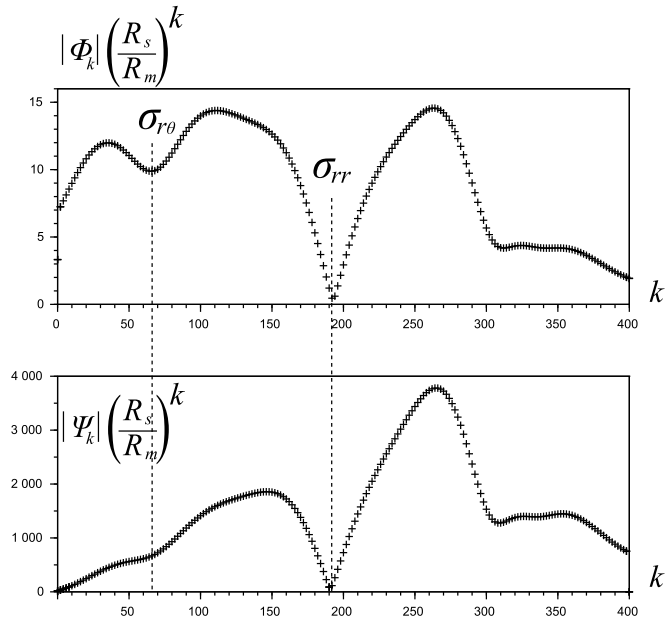

(a) Test 8: amplification factors
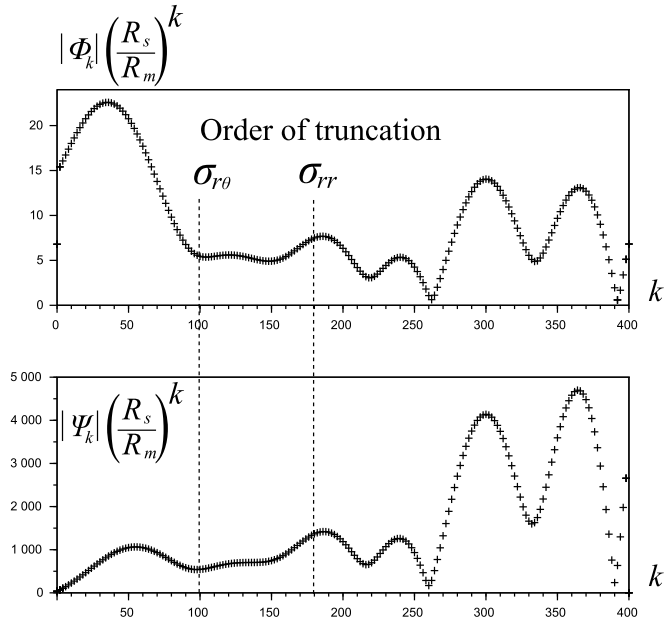

(b) Test 9: amplification factors

Figure 21: Amplification factors and ill-posedness 


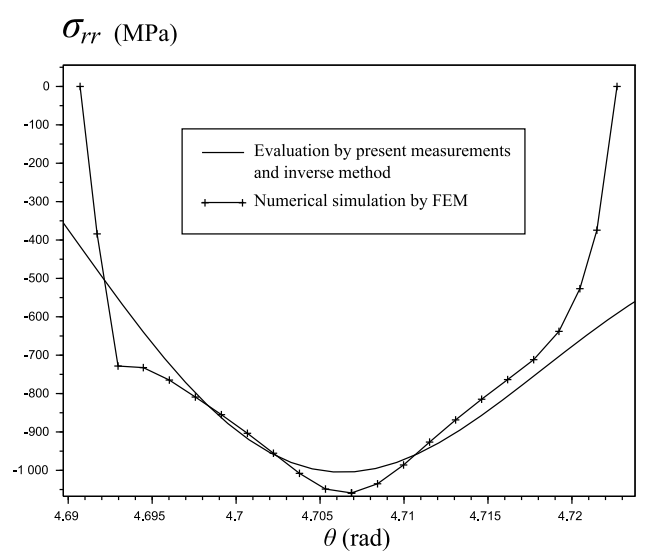

(a) Test 8: contact pressure

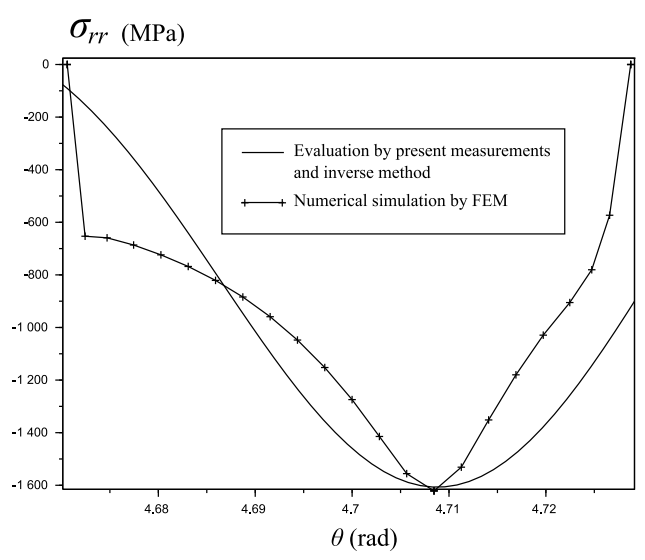

(b) Test 9: contact pressure

Figure 22: Evaluation of contact pressure by inverse method and comparison with numerical simulation

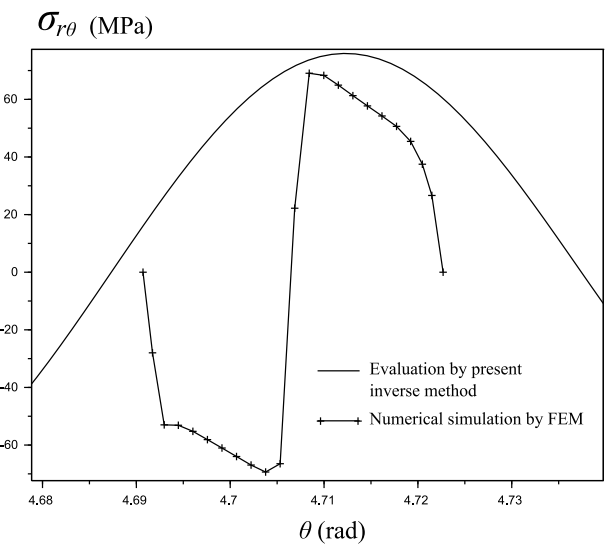

(a) Test 8: contact shear stress

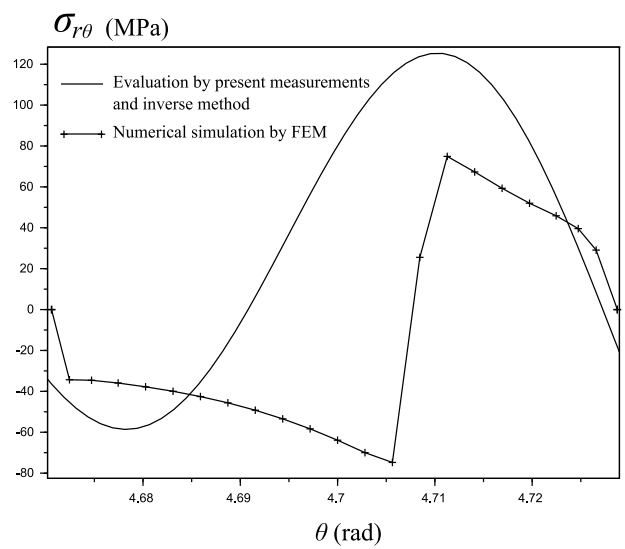

(b) Test 9: contact shear stress

Figure 23: Evaluation of contact shear stress by inverse method and comparison with numerical simulation

\section{Conclusions and perspectives}

In this paper, a technical solution has been developed in order to measure in real time ${ }^{4}$ contact stresses during cold rolling process. The solution is based on inverse analysis that interprets strain measurements done by Optical Fibers Sensors (FBG) inserted inside the roll body (fully embedded). Thus, the main advantage is that contact conditions are not degraded as the strip is not marked in the measurement area (however, strip is marked by the plug contour). The experimental apparatus and technical issues are detailed as well as mathematical developments for the inverse method. Several pilot cold rolling tests have been performed at different rolling speeds (from 25 $\mathrm{m} / \mathrm{min}$ to $400 \mathrm{~m} / \mathrm{min}$ ), different exit applied tension (from 184.7 MPa to 265.2 MPa) and different strip thicknesses (from $2.8 \mathrm{~mm}$ to $0.75 \mathrm{~mm}$ ). Resulting evaluated contact stresses present characteristic pressure peak in the roll gap and sign change for shear stress. Numerical simulations have been performed using the rolling software LAM3 (Hacquin (1996)). Reasonable agreement is obtained between contact pressure evaluated by the inverse method interpreting strain measurements on the one hand and the simulation on the other hand. Therefore, the experimental apparatus coupled with the inverse method are validated and results can be considered relevant for contact pressure. However, shear stress discontinuities predicted by numerical simulations are not reproduced with the inverse method. Thus, shear stress experimental evaluation gives only a satisfactory order of magnitude but not a detailed profile. However, improvements can be expected for shear stress evaluation if the problem on the radial strain measurement is corrected and if fibers strain signals are acquired at a higher frequency of acquisition

${ }^{4} 0.05$ s/cycle: time displayed by Scilab Enterprises (2012) with a quadcore $2.8 \mathrm{GHz}$ 
so that the order of truncation used in the inverse method can be increased, these are being investigated for future trials.

This first indirect measurement of contact stress gives interesting perspectives for the steel industry. Indeed if an industrial version of the sensor can be implemented with sufficient robustness, a close loop control can be proposed in order to monitor and adapt rolling parameters in real time during the process. This paper already demonstrates the applicability of the measurement system and inverse interpretation for semi-industrial conditions. Automation issues should be broached, such as for instance the automatic determination of the order of truncation (for inverse method regularization).

\section{Acknowledgment}

Guillaume Laffont (CEA, LIST, Laboratoire de Mesures Optiques) is acknowledged for producing the Optical Fiber Bragg Gratings used in this study. This work has been performed within the framework of the European project RFS-PR-08501 Advanced roll gap sensors for enhanced hot and cold rolling conditions, which is here gratefully acknowledged for financial support.

\section{References}

Abdelkhalek, S., Montmitonnet, P., Legrand, N., Buessler, P., 2011. Coupled approach for flatness prediction in cold rolling of thin strip. International Journal of Mechanical Sciences 53, 661-675.

Andersen, C., Ravn, B., Wanheim, T., 2001. Development of a commercial transducer for measuring pressure and friction on a model die surface. JMPT 115, 205-211.

Bezerra, L., Saigal, S., 1995. Inverse boundary traction reconstruction with the bem. International Journal of Solids Structures 32, 1417-1431.

Enterprises, S., 2012. Scilab: Free and open source software for numerical computation. Scilab Enterprises, Orsay, France .

Ferdinand, P., Magne, S., Laffont, G., Dewynter, V., Maurin, L., Prudhomme, C., Roussel, N., Giuseffi, M., Maguis, S., 2009. Optical Fiber Sensors from Laboratory to Field Trials: Applications and Trends at CEA LIST. Fiber And Integrated Optics 28, 81-107.

Frieling, G., Walther, F., 2013. Tensile and fatigue properties of fiber-bragg-grating (fbg) sensors. Sensors \& Transducers Journal 154, 143-148.

Hacquin, A., 1996. Modelisation thermo-mecanique tridimensionnelle du laminage: couplage bande-cylindres [3D thermomechanical modelling of rolling processes: coupling strip and rolls]. Ph.D. thesis. Cemef Ecole des Mines de Paris. In French.

Hitchcock, J., 1935. Elastic deformation of rolls during cold rolling. ASME Report of Special Research Committee on Roll Neck Bearings , 33-41.

Jeswiet, J., Rice, W., 1982. The design of a sensor for measuring normal pressure and friction stress in the roll gap during cold rollin, in: Tenth north american manufacturing research conference proceedings, pp. 130-134.

Jiang, Z., Tieu, A., 2001. Modeling of the rolling processes by a 3-D rigid plastic/ visco-plastic finite element method with shifted ICCG method. Comput Struct 40, 79-2727.

Legrand, N., Labbe, N., Weisz-Patrault, D., Ehrlacher, A., Horsky, J., Luks, T., 2012a. Analysis of roll gap heat transfers in hot steel strip rolling through roll temperature sensors and heat transfer models. Key Engineering Materials 504-506, 1043-1048.

Legrand, N., Lavalard, T., Martins, A., 2012b. New concept of friction sensor for strip rolling: Theoretical analysis. Wear 286-287, 8 - 18. Tribology in Manufacturing Processes.

Legrand, N., Weisz-Patrault, D., Labbe, N., Ehrlacher, A., Luks, T., Horsky, J., 2013. Characterization of roll bite heat transfers in hot steel strip rolling and their influence on roll thermal fatigue degradation. Key Engineering Materials 554-557, 1555-1569. 
Lu, C., Tieu, A., Ma, B., Jiang, Z., 2002. Friction measurement in hot rolling of steel, in: 44 th Mechanical Working and Steel Processing Conference and the 8 th International Rolling Conference and International Symposium on Zinc-Coated Steels, pp. 605-614.

Martinez, C., 1999. Étude et réalisation de composants à réseaux de Bragg dans les fibres optiques. Ph.D. thesis. Université de Paris-Sud, Centre d'Orsay, France.

Meierhofer, D., Stelson, K., 1987. Measurement of the interfacial streses in rolling using the elastic deformation of the roll. Journal of engineering for industry 109, 362-369.

Joint Committee for Guides in Metrology, 2012. International vocabulary of metrology - Basic and general concepts and associated terms (VIM). Bureau International des Poids et Mesures. Pavillon de Breteuil, F-92312 Sèvres, France. 3 edition. 2008 version with minor corrections.

Montmitonnet, P., 2006. Hot and cold strip rolling processes. Computer methods in applied mechanics and engineering 195, 6604-6625.

Muskhelishvili, N., 1953. Some basic problems of the mathematical theory of elasticity. Noordhoff International Publishing, Groningen. 2nd edition (1977).

RFS-PR-08051, 2014. Advanced roll gap sensors for enhanced hot and cold rolling processes. European project Final Report.

Schnur, D., Zabaras, N., 1990. Finite element solution of two-dimensional inverse elastic problems using spatial smoothing. International Journal For Numerical Methods In Engineering 30, 57-75.

Shahani, A., Setayeshi, S., Nodamaie, S., Asadi, M., Rezaie, S., 2009. Prediction of influence parameters on the hot rolling process using finite element method and neural network. Journal of materials processing technology 209, 1920-1935.

Wang, M., Yang, H., Sun, Z., Guo, L., 2009. Analysis of coupled mechanical and thermal behaviors in hot rolling of large rings of titanium alloy using 3d dynamic explicit fem. Journal of Materials Processing Technology 209, $3384-3395$.

Weisz-Patrault, D., 2015. Inverse cauchy method with conformal mapping : application to latent flatness defect detection during rolling process. International Journal of Solids and Structures 56, 175-193.

Weisz-Patrault, D., Bock, S., Gürlebeck, K., 2014a. Three-dimensional elasticity based on quaternion-valued potentials. International Journal of Solids and Structures 51, 3422-3430.

Weisz-Patrault, D., Ehrlacher, A., Legrand, N., 2011. A new sensor for the evaluation of contact stress by inverse analysis during steel strip rolling. Journal of Materials Processing Technology 211, 1500-1509.

Weisz-Patrault, D., Ehrlacher, A., Legrand, N., 2012a. Evaluation of temperature field and heat flux by inverse analysis during steel strip rolling. International Journal of Heat and Mass Transfer 55, 629-641.

Weisz-Patrault, D., Ehrlacher, A., Legrand, N., 2013a. Analytical inverse solution for coupled thermoelastic problem for the evaluation of contact stress during steel strip rolling. Applied Mathematical Modelling 37, 2212-2229.

Weisz-Patrault, D., Ehrlacher, A., Legrand, N., 2013b. Evaluation of contact stress during rolling process, by three dimensional analytical inverse method. International Journal of Solids and Structures 50, 3319 - 3331.

Weisz-Patrault, D., Ehrlacher, A., Legrand, N., 2014b. Temperature and heat flux fast estimation during rolling process. International Journal of Thermal Sciences 75, $1-20$.

Weisz-Patrault, D., Ehrlacher, A., Legrand, N., Labbe, N., Horsky, J., Luks, T., 2012b. Experimental study of interfacial heat flux and surface temperature by inverse analysis with thermocouple (fully embedded) during hot steel strip rolling. Advanced Materials Research 452-453, 959-963. 